\title{
TRANSFORMACIONES SOCIOPOLÍTICAS EN LAS CIUDADES DE LA CORONA DE CASTILLA Y EN LAS DEL IMPERIO ALEMÁN DURANTE EL SIGLO XIII ANÁLISIS COMPARATIVO
}

\author{
Máximo Diago HeRnando \\ Institución Milá y Fontanals \\ (CSIC, Barcelona)
}

\begin{abstract}
SUMARIO
I. Auge y decadencia de las "Libertades urbanas" en el Imperio Alemán y en Castilla: 1. Las ciudades alemanas de señorío episcopal. 2. Las ciudades alemanas de señorío regio. 3. Las ciudades castellanas. 4. Novedades en la organización institucional de las ciudades durante el siglo XIII.- II. Transformaciones en la sociedad urbana y presencia de grupos privilegiados en las ciudades: 1. Los ministeriales en las estructuras sociopolíticas de las ciudades alemanas del siglo XIII y el problema de la nobleza urbana. 2. Nobleza y ciudades en Castilla en el siglo XIII.- III. Las Hermandades y Ligas urbanas.
\end{abstract}

El siglo XIII se puede considerar por muchas razones como un período de tránsito entre la plena y la baja Edad Media, por cuanto durante el mismo se produce la culminación de la expansión territorial y socioeconómica de la civilización feudal de la Europa Occidental, y ésta comienza a experimentar una serie de transformaciones que darán como resultado la consolidación de los estados monárquicos, formas de organización política que constituyen uno de los principales legados del mundo bajomedieval a la Europa de la Edad Moderna. Por supuesto estos estados monárquicos no

"Anuario de Istudios Medievales". 27 (1997) 
llegaron a consolidarse en todos los ámbitos territoriales de la Europa occidental medieval, y en ningún caso respondieron a formas de organización idénticas de unos a otros, aunque entre bastantes de ellos sí que se pueden constatar bastantes paralelismos. En concreto un sector territorial muy importante que no evolucionó conforme a este modelo fue el que abarcaba el Imperio, al norte y al sur de los Alpes, donde en lugar de un estado monárquico más o menos centralizado se consolidaron numerosos principados de mayor o menor extensión, repúblicas urbanas y otros múltiples enclaves jurisdiccionales de diversa naturaleza'. Pero aquí también representó el siglo XIII el período clave en que se decidió la orientación del modelo de organización sociopolítica de este ámbito territorial, proyectándose las consecuencias de esta "elección" hasta el propio siglo XIX.

Por esta razón presenta un gran interés profundizar en el análisis de las transformaciones políticas ocurridas en los distintos ámbitos de la Europa occidental durante el siglo XIII, en especial desde un punto de vista comparativo, para así contribuir a la comprensión de las divergencias en las formas de evolución política de los distintos territorios que conforman el ámbito de civilización europeo occidental, que en muchos casos proyectan sus consecuencias hasta la actualidad, incidiendo por ejemplo en el propio proceso de integración europea que se está tratando de promover por amplios sectores políticos y sociales.

En este contexto resulta particularmente interesante comparar dos ámbitos territoriales que en el siglo XIII tomaron dos rumbos de evolución muy dispares, precisamente en un momento en que los contactos políticos entre ambos, que hasta entonces habían sido muy escasos, se intensificaron. Nos estamos refiriendo en concreto al reino de Castilla y al Imperio romanogermánico, que primero a través del matrimonio de Fernando III con Beatriz de Suabia, y luego sobre todo a raíz de la defensa de su candidatura a la dignidad imperial por Alfonso X, conocieron a mediados del siglo XIII una fase de más intensos contactos diplomáticos², precisamente cuando las formas de organización política de ambos territorios estaban comenzando a

\footnotetext{
'Ofrecemos una visión de conjunto sobre las realizaciones concretas de la institución imperial en el Occidente medieval en El Imperio en la Europa Medieval, Arco-Libros, Madrid, 1996. Sobre la complicada geografía política del Imperio al norte de los Alpes da idea la lectura de la obra de Gerhard KOEBLER, Historisches Lexikon der deutschen Länder. Die deutschen Territorien vom Mittelalter bis zur Gegemwart. Múnich, 1988.

¿Vid. nuestro artículo, La monarquía castellana y los Staufer. Contactos políticos y diplomáticos en los siglos XII y XIII, "Espacio, Tiempo y Forma", 8 (1995), pp. 51-84.
} 
discurrir por senderos muy distantes entre sí. Y es que, en efecto, mientras que en Castilla con Alfonso X se trató de poner en práctica por primera vez un abanico de fórmulas de gobierno propias de un "estado moderno", que potenciaban la uniformización y la centralización, en el Imperio por el contrario el Interregno abrió un proceso de intensificación de las tendencias hacia la disgregación política y jurisdiccional del territorio, que dio lugar a la consolidación por un lado de unos cuantos grandes principados territoriales, organizados internamente conforme al modelo de los grandes estados monárquicos europeos, y por otro de un sinfín de pequeñas unidades jurisdiccionales de carácter muy diverso, desde prósperas "repúblicas urbanas" hasta diminutos señoríos rurales de pequeña nobleza o de monasterios.

En este proceso de profundas transformaciones que tuvo lugar en Castilla y en el Imperio alemán desde mediados del siglo XIII las ciudades fueron quizás las que más intensamente experimentaron las consecuencias de los cambios. Y, en efecto, fue en el siglo XIII cuando las entidades urbanas de estos dos ámbitos entraron por dos vías de evolución muy divergentes, que les llevaron a consolidarse como realidades sociopolíticas de características muy opuestas. De hecho las circunstancias en las que había tenido lugar el proceso de "urbanización" en estos dos ámbitos habían dado lugar a que las ciudades de uno y otro respondiesen a modelos muy diferentes ya en los siglos XI y XII, pero el fenómeno singular que tuvo lugar en el siglo XIII consistió en que los dos modelos experimentaron una notable inflexión en su orientación evolutiva. Y así en Castilla las ciudades, que con anterioridad habían disfrutado de amplios márgenes de autonomía política y habían conocido una estructura social uniforme en la que predominaba el elemento libre, pasaron a convertirse en entidades muy dependientes o bien del poder regio o bien de los poderes señoriales, en las que además se rompió el principio de uniformidad sociojurídica de sus habitantes, al establecerse una fractura estamental entre hidalgos y pecheros. Y por el contrario en el Imperio alemán la mayoría de las ciudades, que en su origen habían conocido una situación de enorme diversificación de la condición sociojurídica de su población, con predominio de los elementos de condición servil, y de total dependencia con respecto a los poderes señoriales, consolidaron en el transcurso del siglo XIII el disfrute de una amplia autonomía política, al 
tiempo que sus habitantes tendían a adquirir un estatuto jurídico uniforme, perdiendo toda marca de condición servil ${ }^{3}$.

\section{AUgE Y DECADENCIA DE LAS "LIBERTADES URBANAS" EN EL IMPERIO ALEMÁN Y EN CASTILLA}

\section{Las ciudades alemanas de señorío episcopal}

Durante los primeros siglos medievales todos los núcleos existentes en el ámbito del Imperio alemán con características urbanas más o menos perceptibles, que en su mayoría retrotraían sus orígenes a época romana y eran urbes episcopales, conocieron una situación de sometimiento a poderes señoriales similar a la de los núcleos rurales. Y del mismo modo las numerosas ciudades que a partir del siglo XI fueron fundadas ${ }^{4}$ por estos mismos poderes señoriales estuvieron en sus primeras fases intensamente sometidas al control político de éstos, que sólo se mostraron proclives a conceder privilegios de carácter socioeconómico a sus pobladores, para favorecer un rápido desarrollo económico y demográfico de estos núcleos, pero fueron mucho más reacios a renunciar, aunque sólo fuese parcialmente, a su capacidad de ejercer el control político sobre los mismos ${ }^{5}$.

El proceso de "despertar político" de las ciudades en el Imperio alemán se inició de hecho muy tarde, y fue el conflicto de las Investiduras, en el tránsito del siglo XI al XII, el que por primera vez creó condiciones propicias para que unas pocas comunidades urbanas, sobre todo renanas, comenzasen a mostrar abiertamente su malestar ante su situación de

\footnotetext{
${ }^{3}$ Estas tesis las desarrollamos más ampliamente en Las ciudades en Castilla y en el Imperio alemán (Análisis comparativo de su perfil juridico), "AHDE" (1995), pp. 1037-1070. También en parte en El perfil socioeconomico de los grupos gobernantes en las ciudades bajomedievales. análisis comparativo de los ejemplos castellano y alemain. "En la España Medieval", 18 (1995), pp. $85-134$.

${ }^{4}$ Se entiende por fundación de una ciudad la concesión de privilegios a una comunidad ya instalada en un núcleo de población preexistente, o en proceso de instalación en un núcleo creado "ex novo". Esta última situación se dio con menos frecuencia.

${ }^{5}$ Un buen ejemplo de esta política lo ofrecen los emperadores de la dinastía Staufer, que fueron fundadores y señores directos de multitud de ciudades durante el siglo XII y primera mitad del XIII. Vid. F. OPL. Stadt und Reich im 12. Jahrhundert (1125-1190). Viena-ColoniaGraz, 1986. Y B. Diestelk kAMP. König und Städte in Salischer Ind Stanfischer Zeit. Regmum Teutonicum, "Historische Zeitschrift". Anexo 7 (1982), pp. 247-97.
} 
sometimiento al poder señorial ${ }^{6}$. Así en 1074 los ciudadanos de Colonia se sublevaron contra su señor el arzobispo, a raíz de haber confiscado éste el barco de un mercader, y le obligaron incluso a tener que abandonar la ciudad y refugiarse en la cercana Neuss ${ }^{7}$. Y pocos años después, en 1077, hubo desórdenes en Maguncia, a raíz de la coronación en esta ciudad de Rodolfo, el rey elegido a instancias del papa y de los príncipes contrarios al emperador Enrique IV, y al que en aquel momento apoyaba el arzobispo maguntino, señor de la ciudad, en contra de la opinión de la población urbana, que simpatizaba con Enrique IV, por lo que también en esta ocasión, como antes en Colonia, el arzobispo se vio obligado a huir de la ciudad, junto con el rey Rodolfo ${ }^{8}$.

Estos episodios de la década de 1070 son testimonio de la existencia de una situación de tensión más o menos larvada en diversas ciudades de señorío episcopal alemanas, pero en ningún caso pueden ser considerados como actos que sancionan la consolidación de las primeras comunidades políticas urbanas propiamente dichas en el ámbito alemán, ya que estas ciudades, que de hecho fueron las pioneras en el proceso de adquisición de formas de autogobierno, tuvieron, no obstante, que esperar mucho tiempo hasta lograr una independencia total de facto frente a sus señores, que nunca fue alcanzada antes del siglo XIII, sin duda el siglo por excelencia de la consolidación de las ciudades como entidades políticas autónomas en el ámbito del Imperio alemán.

En Worms ya se empieza a constatar la existencia de la institución del consejo ciudadano (Rat) en 1198 y de nuevo en 1202, pero durante la primera mitad del siglo XIII continuó planteada la rivalidad entre el obispo y la población urbana en torno al control de esta institución, produciéndose diversas alternativas en este conflicto, relacionadas en muchos casos con la evolución de los acontecimientos políticos en el Imperio. Y así por ejemplo

\footnotetext{
"Una visión de conjunto del proceso, enmarcado además en el contexto europeo, en Knut Schulz. "Denn sie lieben die Freiheit so sehr..." Kommunale Aufstände und Entstehung des europäischen Bürgertums im Hochmittelalter, Darmstadt, 1992.

${ }^{7}$ Este episodio ha sido analizado en multitud de trabajos. Vid. entre otros Edith ENNEN. Erzbischof und Stadtgemeinde in Köln bis zur Schlacht von Worringen (1288), "Gesammelte Abhandlungen zum europäischen Städtewesen und zur rheinischen Geschichte", Bonn, 1977, pp. 388-404.

${ }^{8}$ Vid. entre otras muchas obras que analizan éste y otros episodios de la historia urbana alemana vinculados a la lucha de las Investiduras. Ph. DOLLINGER, Der Aufschwung der oberrheinischen Bischofsstädten in salischer Zeit (1025-1125), en B. DIESTELKAMP (Ed.) "Beiträge zum hochmittelalterlichen Städtewesen", Colonia-Viena, 1982, pp. 134-148.
} 
el obispo consiguió en 1232 que el emperador le encargase la destrucción del edificio del ayuntamiento (Rathaus), símbolo de identificación de la comunidad política urbana. Pero por el contrario pocos años más tarde, en 1235, a raíz de la deposición del rey Enrique VII, hijo de Federico II, la posición política del obispo, que había sido aliado del monarca depuesto, sufrió un serio contratiempo, mientras que en contrapartida se reforzaba la capacidad de intervención del emperador, aunque tras la reconciliación entre ambos aquél intentó de nuevo ampliar su derechos señoriales en la ciudad. En concreto durante estos años se plantearon graves diferencias de criterio entre el obispo y la comunidad política urbana sobre el régimen de constitución del consejo, dado que esta última abogaba por un consejo de 40 miembros, mientras que el obispo deseaba reducirlo a 12 , de renovación anual y nombrados personalmente por él ${ }^{9}$. Después de la muerte de Federico II las oportunidades que se ofrecieron a Worms para consolidar su autonomía política fueron muchas, y la fecha de 1254 tuvo una importancia clave, ya que fue entonces cuando esta ciudad y la de Maguncia tomaron los acuerdos preliminares para la constitución de la célebre Liga Renana (Rheinischer $B u n d)$, a la que luego se adhirieron un gran número de ciudades, y también de príncipes y nobles ${ }^{10}$.

Para Maguncia, también ciudad de señorío episcopal, estos años del Interregno y de la Liga Renana tuvieron igualmente una importancia clave en el proceso de su consolidación como comunidad política autónoma, pero ya con anterioridad se habían dado pasos importantes en este sentido, como por ejemplo cuando en 1244 el arzobispo concedió un privilegio a la ciudad que estableció los presupuestos jurídicos para la constitución de un consejo de 22 ciudadanos ${ }^{11}$. Maguncia, sin embargo, fue una de las pocas ciudades que, después de haber llegado a alcanzar la posición de ciudad libre y de disfrutarla durante dos siglos aproximadamente, terminó perdiendo más adelante su autonomía, concretamente en 1462, al ser derrotada en un

"Vid. Burkard KeILmann, Der Kampf um die Stadtherrschaft in Worms wälrend des 13. Jahrhunderts, Darmstadt-Marburg, 1985, en particular p. 73.

${ }^{10}$ Planitz propone la fecha de 1254 para fijar el momento de consolidación de Worms y Maguncia como ciudades libres, por lo que cabe presumir que para él la concertación de la Liga fue el acto que sancionó la consolidación de estas ciudades como comunidades políticas autónomas. Vid. Die deutsche Stadt des Mittelalters. Von der Römerzeit bis zu den Zunftkämpfen, Graz-Colonia, 1954, p. 183.

"Vid. Dieter DEMANDT, Stadtherrschaft und Stadtreiheit im Spannungsfeld von Geistlichkeit und Bürgerschaft in Mainz (11.-15. Jahrhundert), Wiesbaden, 1977, p. 47. 
enfrentamiento militar la comunidad política urbana por el arzobispo maguntino Adolfo de Nassau, tras haber optado la primera por apoyar a otro candidato para la sucesión en la silla arzobispal ${ }^{12}$.

Entre las ciudades para las que Planitz indica la fecha de 1254 como el momento en que ascendieron a la categoría de ciudades libres, figura también la de Spira, tal vez por su temprana incorporación a la Liga Renana. No obstante, según han demostrado algunas monografías dedicadas a la historia política de esta ciudad en el siglo XIII, el conflicto político entre la comunidad urbana y el obispo se prolongó bastante más allá de los años del Interregno y de la Liga Renana, no quedando definitivamente resuelto en favor de la primera hasta finales de siglo. Así por ejemplo en 1258 se dejó de nuevo en manos del obispo la función de designar a los 18 miembros del consejo ciudadano, pero en 1281 este consejo aprobó un estatuto por el que se disponía que en adelante ningún oficial del obispo pudiese ser miembro del mismo. Y ya de forma definitiva un tratado firmado en 1294 marcó el fin del señorío episcopal sobre la ciudad, al renunciar el obispo a ejercer su derecho al cobro de impuestos en la misma, y a intervenir en el nombramiento de los oficiales urbanos, tanto de administración como de justicia, aunque se siguió reservando el derecho de su confirmación ${ }^{13}$.

En otras ciudades el momento que marcó el final del señorío episcopal sobre las mismas se ha podido fijar en fechas más precisas y emblemáticas porque se llegaron a plantear enfrentamientos armados entre la comunidad pulítica urbana y la autoridad señorial, que tuvieron como desenlace una clara y rotunda derrota militar del señor. Fue lo que ocurrió primero en Estrasburgo, donde la población ciudadana, contando con el apoyo del conde Rodolfo de Habsburgo, futuro rey de Romanos, infligió una severa derrota a su obispo en Hausbergen en 1262, obligándole a raíz de ello

\footnotetext{
'Vid. Anton Ph. BRUECK. Mainz lom Verlust der Stadtreiheit bis zum Ende des Dreissigjährigen Krieges. 1462 bis 1648. Düsseldorf. 1972. Y Dieter DEMANDT, op. cit. pp. 153-5. Hay una evidente confusión en J.M ${ }^{\mathbf{a}}$. MONSALvo ANTÓN cuando sostiene que Maguncia no vio reconocido su estatuto de ciudad libre hasta bien entrado el siglo XV, siendo que fue precisamente entonces cuando lo perdió. Vid. su reciente obra de síntesis Las ciudades europeas del Mediev'o, Editorial Síntesis. Madrid, 1997, p. 184.

${ }^{13}$ Vid. Ernst VolTMER, Reichsstadt und Herrschaft. Zur Geschichte der Stadt Speyer im hohen und späten Mittelalter. Tréveris, 1981, pp. 37-8, 54 y 56. Llama la atención este autor sobre el hecho de que en Spira, a diferencia de otras ciudades como Colonia. Worms o Maguncia, no hubo conflictos entre el señor y la población urbana con anterioridad al siglo XIII, y que el señorío estuvo en gran medida compartido entre el obispo y el emperador hasta la caída de los Staufer.
} 
a abandonar para siempre la ciudad en compañía de muchos de sus ministeriales, sobre todo de los de mayor rango ${ }^{14}$. Y años más tarde fue la población ciudadana de Colonia la que en la batalla de Worringen del año 1288 luchó en el bando contrario al de su señor el arzobispo ${ }^{15}$, y aprovechó su victoria en aquel enfrentamiento armado para imponer a los arzobispos colonienses la obligación de residir fuera de la ciudad, aunque ya antes de esta fecha la comunidad política urbana había alcanzado amplias cuotas de autonomía ${ }^{16}$. A partir de entonces fue en la cercana ciudad de Bonn donde se establecieron los arzobispos colonienses hasta el siglo XIX, aunque siguieron realizando visitas esporádicas a Colonia, y durante los siglos bajomedievales mantuvieron en vigor la práctica de efectuar a comienzos de su pontificado una entrada triunfal en la ciudad, en el trasncurso de la cual obligaban a la población coloniense a rendirles homenaje como a sus señores ${ }^{17}$. De hecho la situación de Colonia no llegó a quedar bien definida desde el punto de vista jurídico, y aunque dos siglos después de Worringen el emperador Federico III le terminó concediendo un privilegio, por el que se le reconocía como ciudad imperial, prohibiendo que en adelante se prestase homenaje al arzobispo, las entradas arzobispales, en el transcurso de las cuales se prestaba el homenaje, se siguieron practicando, al menos en unas cuantas ocasiones después de la concesión del privilegio.

\footnotetext{
${ }^{14}$ Sobre el apoyo de Rodolfo de Habsburgo Vid.Th. MARTIn, Die Städtepolitik Rudolfs von Habsburg. Göttingen, 1976, p. 36. Las obras que han entrado en valorar la significación histórica de la batalla de Hausbergen para Estrasburgo son muy numerosas y resultaría aquí prolijo citarlas todas. Hay desacuerdo entre los autores sobre las implicaciones que pudo tener para la futura conformación de la comunidad política urbana el abandono de la ciudad por algunos ministeriales del obispo.

${ }^{15} \mathrm{El}$ conflicto al que puso fin la batalla de Worringen, suscitado en torno a la sucesión de Limburg, enfrentaba por un lado al duque de Brabante, apoyado por la ciudad de Colonia, y por otro al conde de Gueldres, apoyado por el arzobispo de Colonia. Sigfrido de Westerburg. Resultó victorioso el duque de Brabante. Vid. Hugo STEHKÄMPER. Die Stadt Köln und die Schlacht bei Worringen. "Blätter für deutsche Landesgeschichte", 124 (1988), pp. 311-406.

"Sobre el proceso de consolidación de la comunidad política urbana, y ampliación de sus atribuciones frente al poder señorial. en Colonia antes de 1288 tratan extensamente Edith ENNEN, Erabischof und Stadtgemeinde in Köln bis zur Schlacht von Worringen (1288), "Gesammelte Abhandlungen zum europäischen Sädtewesen und zur Rheinischen Geschichte". Bonn, 1977, pp. 388-404. Y Hugo STEHKÄMPER, Uber die rechtliche Absicherung der Stadt Köln gegen eine erzbischöfliche Landesherrschaft vor 1288, en " Die Stadt in der europäischen Geschichte. Festschrift Edith Ennen". Bonn, 1972. pp. 343-377.

${ }^{17}$ Vid. Klaus MILITZER, Die feierlichen Einritte der Kölner Erzbischöfe in die Stadt Köln im Spritmittelalter, "Jahrbuch des Kölnischen Geschichtsvereins", 55 (1984), pp. 77-116.
} 
La batalla de Worringen tuvo lugar durante el reinado de Rodolfo de Habsburgo, pero él no intervino apenas en el conflicto al que ésta dio fin. Este monarca, no obstante, ayudó a que en algunas otras ciudades de señorío episcopal triunfase el deseo de independización de la comunidad política urbana frente al poder señorial, adoptando así una política un tanto distinta de la de sus antecesores Staufer. Y así si ya hemos visto que en el caso de Estrasburgo en 1262 apoyó la causa de la ciudad frente al obispo, por otro lado advertimos que su intervención en Basilea fue todavía más decisiva para conseguir su conversión en una ciudad libre ${ }^{18}$. Pero hay que tener en cuenta que en ambos casos se trataba de ciudades muy próximas a sus territorios patrimoniales, lo cual contribuye a explicar su interés en debilitar la posición política de los obispos, con los que rivalizaba por la consecución de la hegemonía en la zona.

Además de las mencionadas, otras importantes ciudades de señorío episcopal llegaron a alcanzar la categoría de libres en el transcurso del siglo XIII, como por ejemplo Ratisbona ${ }^{19}$, Augsburgo ${ }^{20}$, y Magdeburgo, y ya bien entrado el siglo XIV, en 1370, Constanza, ciudad que por lo demás disfrutó poco tiempo de esta libertad ya que en 1549 pasó a quedar bajo dominio de los Habsburgo. Y por otra parte a éstas habría que añadir las del ámbito de habla francesa de Besançon, Toul, Metz, Verdun y Cambrai.

Por supuesto hubo también importantes ciudades que, aun habiendo demostrado tempranamente un cierto espíritu de beligerancia contra sus señores, no llegaron a dejar de depender de la autoridad de éstos hasta el final del Antiguo Régimen. Y uno de los ejemplos más ilustrativos en este sentido nos lo proporciona Tréveris, que nunca alcanzó la categoría de

\footnotetext{
${ }^{18}$ Th. MARTIN, op. cit., pp. 29-31. Y Reinhard PATEMAnN, Die Stadtentwicklung von Basel bis zum Ende des 13. Jahrhunderts, "Zeitschrift für die Geschichte des Oberrheins", 112 (1964), pp. 431-467.

${ }^{19}$ Sobre la compleja trayectoria de Ratisbona en época medieval Vid. Peter SCHMID, Regensburg. Stadt der Könige und Herzöge im Mittelalter, Kallmünz, 1977. Y del mismo autor Die Anfünge der regensburger Bürgerschaft und ihr Weg zur Stadtherrschaft, "Zeitschrift für bayerische Landesgeschichte", 45 (1982), pp. 483-539.

${ }^{20} \mathrm{Algunos}$ autores fijan convencionalmente en 1276 la fecha de conversión de esta ciudad en libre. De hecho se trataba de una ciudad en la que el emperador había compartido derechos señoriales con el obispo, puesto que los Staufer controlaban el oficio del Vogt, que ejercía la alta jurisdicción, desde 1168. Además de Augsburgo compartieron esta condición, siendo identificadas por tanto como Reichsiogteistïdte, Constanza, Basilea y Chur. Vid. Gisela MÖNCKE, Bischofsstadt und Reichsstadt. Ein Beitrag zur mittelalterlichen Satdtverfassung von Augsburg, Konstanz und Basel. Universidad Libre de Berlín (Tesis doctoral), 1971.
} 
ciudad libre, aunque en el transcurso del siglo XII la comunidad política urbana había sido allí muy beligerante contra su señor el arzobispo ${ }^{21}$.

\section{Las ciudades alemanas de señorio regio}

Así como el proceso de reivindicación de derechos políticos por parte de las comunidades urbanas se puede rastrear entre las ciudades de señorío episcopal en casos extremos incluso en las décadas finales del siglo XI, aunque sólo sea de forma muy balbuciente, las ciudades de señorío regio no manifestaron ningún tipo de iniciativa en este terreno hasta prácticamente el final de la era de los Staufer, a mediados del siglo XIII. No es cierto por lo tanto, según ha sostenido recientemente el profesor Monsalvo Antón, que para las ciudades dependientes del emperador el reinado de Federico I supusiese la definitiva regularización de los derechos y libertades ciudadanas según su estatuto, mientras que desde Federico II ya no se habría avanzado nada en la línea de obtención de libertades ${ }^{22}$. Los autores que han analizado la política de Barbarroja hacia sus ciudades, e incluso hacia las de señorío episcopal en cuyos asuntos internos intervino, en ningún caso han comprobado que este monarca se caracterizase por simpatizar con el proyecto de potenciación de las libertades políticas urbanas, sino más bien por todo lo contrario. De hecho intervino en más de una ocasión en ciudades de señorío episcopal para reprimir algunos movimientos políticos dirigidos contra la posición de los obispos como señores ${ }^{23}$. Y en las ciudades colocadas directamente bajo su señorío ni siquiera tuvo necesidad de realizar este tipo de intervenciones, porque en las mismas no se había alcanzado todavía en su época un mínimo grado de vertebración de las comunidades políticas urbanas, que por lo tanto nunca llegaron a desafiar su autoridad ${ }^{24}$. De

\footnotetext{
${ }^{21}$ Vid. Knut Schulz. Ministerialitït und Bürgertum in Trier. Bonn, 1968. Y para la época bajomedieval Michael MATHEUS. Trier am Ende des Mittelalters. Studien zur Sozial-, Wirtschafts- und Verfassungsgeschichte der Stadt Trier vom 14. bis 16. Jahrhundert, Tréveris, 1984.

${ }^{2}$ Vid. J.Ma . MONSALvo ANTÓN, Las ciudades europeas, p. 181.

${ }^{23}$ Prohibió en dos ocasiones el establecimiento de la comuna en Tréveris, en 1157 y en 1161. Vid. K. Schulz, Ministerialität und Bürgertum in Trier, Bonn, 1968, p. 57. En Maguncia, tras el asesinato del arzobispo por la población ciudadana en 1160, impuso un severo castigo y mandó derribar las murallas de la ciudad. Vid. Dieter DEMANDT, op. cit. p. 61.

${ }^{24}$ Para una visión global de las relaciones de Federico I y otros monarcas alemanes del siglo XII con las principales ciudades del Imperio, tanto de señorío episcopal como de señorío regio vid. Ferdinand OPL, Stadt und Reich im 12. Jahrhundert (1125-1190), Viena-Colonia-Graz,
} 
hecho, no hay que olvidar que la población de algunas ciudades de señorío regio alemanas, como Frankfurt, Wetzlar, Friedberg o Gelnhausen tuvo que esperar hasta bien avanzado el reinado de Federico II para acceder al disfrute de la plena libertad personal ${ }^{25}$. Y éste era un requisito fundamental para después aspirar a la consecución de la libertad política, que de hecho ninguna ciudad de señorío regio persiguió en Alemania con un mínimo de decisión antes de la muerte del emperador Federico II, en claro contraste con lo que venía ocurriendo en las ciudades de señorío episcopal desde hacía bastante tiempo. Y de ahí que las ciudades de señorío regio desempeñasen un papel muy poco relevante en la Liga Renana, dominada por las ciudades de señorío episcopal en vías de convertirse en ciudades libres.

De hecho si nos centramos en el caso de una de las ciudades de señorío regio que en los siglos bajomedievales tuvo una trayectoria política más dinámica y persiguió objetivos más ambiciosos, la de Nürnberg, podemos constatar que en ella el proceso de conformación de la comunidad política urbana no se inició hasta la década de 1240. Entonces, aprovechando el conflicto entre el emperador y el papa, la que sólo había sido una comunidad privilegiada en el ámbito del derecho privado comenzó a dar los primeros pasos para constituirse en una comunidad política propiamente dicha, capaz de asumir atribuciones de gobierno, que hasta entonces habían sido ejercidas exclusivamente por los oficiales señoriales designados por el rey. Pero el proceso fue largo y no culminó hasta principios del siglo $\mathrm{XV}$, si bien los años del Interregno fueron decisivos para propulsarlo, y en 1282 la ciudad ya había conseguido imponerse al que en las décadas previas había sido su principal rival, el tenente de la fortaleza imperial, quien aprovechando el vacío de poder creado a la muerte de Federico II había intentado labrarse en torno a Nürnberg un principado territorial ${ }^{26}$.

En Nürnberg es en 1256 cuando por primera vez aparecen mencionados los cónsules, y la mayoría de las ciudades que habían estado en relación de dependencia señorial hacia los Staufer, adoptaron esta institución en fechas todavía más tardías. Y éste no es sino uno entre

1986.

${ }^{25}$ Fue en 1232 cuando el rey Enrique VII, primogénito del emperador Federico II, concedió privilegio a los vecinos de estas ciudades para que en el futuro pudiesen elegir libremente a sus esposas. Vid. Fred Schwind, Die Landvogtei in der Wetterau, Marburg, 1972, p. 15.

${ }^{26}$ Vid. Ernst PITZ, Die Entstehung der Ratsherrschaft in Nürnberg im 13. und 14. Jalhrhundert, Múnich, 1956, pp. 4 y ss. 
múltiples indicios que demuestran que fue el vacío de poder producido en Alemania durante los años del Interregno, tras la muerte de Federico II, el que favoreció el inicio del proceso de "asalto" a las instituciones de gobierno y jurisdicción locales por parte de la población urbana en las ciudades de señorío regio, que en la mayoría de los casos no culminó hasta bien entrado el siglo XIV, cuando quedaron bajo control ciudadano los oficios de jueces (Schultheissen). Y sólo excepcionalmente alguna ciudad de señorío regio consiguió ya en vida de Federico II amplias cotas de autonomía, como fue el caso de Lübeck, a la que éste concedió un importante privilegio en 1226, que sancionó su conversión en ciudad imperial (Reichsfreiheitsprivileg) ${ }^{27}$.

Ciertamente Rodolfo de Habsburgo, en sus intentos de restaurar el imperio de los Staufer, dio algunos pasos para tratar de recuperar la capacidad de intervención que éstos habían tenido en sus ciudades, pero fracasó en el intento, y sus sucesores no tuvieron más suerte que él, en las pocas ocasiones en que se preocuparon por intervenir en la vida política urbana. En efecto, Rodolfo I tuvo que hacer frente en más de una ocasión a rebeliones de ciudades, como la que tuvo lugar en los años 1275-6, que fue especialmente virulenta en Alsacia, Wetterau y Turingia, y la que estalló más adelante en 1284, por problemas de política fiscal y por sus intentos de revitalizar los castillos imperiales localizados en entornos urbanos, aunque en el fondo estos conflictos respondían más que a una abierta hostilidad hacia la monarquía a un deseo de evitar que la nobleza dispusiese de plataformas para intervenir en la vida política interna de las comunidades urbanas, como eran de hecho algunos de los referidos castillos ${ }^{28}$. Y finalmente el monarca debió ceder ante la presión de las ciudades, hecho que tuvo su traducción por ejemplo en la práctica desaparición de los castillos, principal elemento

${ }^{27}$ Vid. Georg Wilhelm VON BRANDT, Vogtei und Rektorat in Lübeck während des 13. Jahrhunderts, "Blätter für deutsche Landesgeschichte", 107 (1971), pp. 162-201. En el privilegio concedido por Federico II a Lübeck la califica expresamente de libera civitas y locus imperii. Este mismo monarca en un privilegio concedido a Viena en 1237 la llama civitas imperialis. Vid. Hans PlaNITZ, op. cit. p. 181. Estas denominaciones sólo se generalizarian después del Interregno, denotando la transformación de las antiguas ciudades de señorío regio en entidades autónomas que formaban parte del cuerpo político del imperio. Hay que hacer notar que Viena, a pesar de haber sido tan tempranamente privilegiada, no consiguió consolidarse como ciudad imperial, quedando bajo dominio de los Habsburgo, que la convirtieron en su capital.

${ }^{28}$ Nos referimos más por extenso a este fenómeno en El papel de los castillos en las ciudades de señorio regio en Castilla y en el Imperio alemán. Análisis comparativo. Siglos XII$X V$, "Estudios de Historia y de Arqueología Medievales", 11 (1996), pp. 85-129. en particular pp. 110 y ss. Vid. también Th.MarTin, Die Städtepolitik. 
identificador del poder señorial, de todas las ciudades de señorío regio que habían contado con ellos.

$\mathrm{Y}$ por tanto no es pura casualidad que a partir del reinado de Rodolfo I se empezase a imponer la denominación de civitas imperii o ciudad imperial (Reichsstadt) para las que hasta entonces habían sido simples ciudades de señorío regio, cambio que venía a poner de manifiesto que éstas habían alcanzado un nuevo estatuto, consolidándose como comunidades políticas integradas en el cuerpo del imperio, cuando antes sólo habían sido agrupaciones de vasallos dependientes de un señor, que era el rey ${ }^{29}$.

En conjunto a fines del siglo XIII las principales ciudades alemanas, tanto de señorío regio como episcopal, se habían consolidado, pues, como comunidades políticas autónomas, aunque estas últimas tras una larga trayectoria reivindicativa, repleta de episodios de enfrentamientos a veces violentos, que se remontaba a finales del siglo $\mathrm{XI}$, mientras que las primeras habían consiguido sus objetivos mucho más tarde, pero también de una forma más pacífica, aprovechando el derrumbe del poder regio a mediados del siglo XIII.

En adelante unas y otras, en calidad de ciudades imperiales y ciudades libres ( Reichs- y Freistädte) ${ }^{30}$, serían protagonistas destacadas de la historia política del Imperio en los siglos XIV y XV, aunque los príncipes territoriales y la nobleza imperial siempre las consideraron de rango político

\footnotetext{
${ }^{29}$ No estamos de acuerdo con el punto de vista que sobre esta cuestión propone J.M ${ }^{\mathbf{a}}$. MONSAlvo ANTón, en Las ciudades europeas, p. 183. Tiende a confundir en exceso los conceptos de ciudades de señorío regio y ciudades imperiales (Reichsstädte), cuando habría que diferenciarlos porque hacen referencia a dos momentos distintos de la historia de estas ciudades alemanas, el anterior al Interregno, cuando estaban sometidas a una fuerte relación de dependencia señorial, y el posterior al mismo, cuando se consolidaron como ciudades con alto grado de autonomía. En consecuencia resulta distorsionador afirmar que bastantes ciudades imperiales sólo eran "ciudades del tipo Landstädte procedentes de los dominios y residencias de los Honhenstaufen, convertidas en imperiales al recaer la dinastía imperial en esta familia durante los siglos XII-XIII". Para rebatir esta tesis habría que entrar en una larga disquisición sobre la historia constitucional del Imperio alemán medieval, pero de momento baste con señalar que entendemos que el período clave que determinó la conversión de las ciudades en imperiales fue el del Interregno, con un breve preludio en el reinado de Federico II, cuando este monarca concedió el privilegio de ciudad imperial a Lübeck y Viena. Estas dos ciudades fueron privilegiadas, y no incorporadas como sugiere MONSALVO, aunque de hecho luego Viena perdió sus privilegios y se consolidó como una Landstadt sometida a los Habsburgo. Para evitar confusiones hay que tener en cuenta que en los siglos bajomedievales y en la Edad Moderna se diferenció perfectamente entre ciudades imperiales y ciudades patrimoniales de la dinastía imperial gobernante, ya fuese ésta la de los Habsburgo, la de los Wittelsbach o la de los Luxemburgo.

${ }^{30}$ Sobre lo problemático de la diferenciación entre estos dos conceptos vid. G. MÖNCKE, op. cit. pp. 230 y ss.
} 
inferior, y consiguieron relegarlas a una posición de segunda fila en las instituciones del Imperio, como por ejemplo el Reichstag ${ }^{31}$.

Hay que tener en cuenta, no obstante, que además de estas ciudades imperiales y libres hubo en Alemania otras muchas, de hecho la mayoría, que permanecieron sometidas al poder señorial, representado en la mayor parte de los casos por príncipes territoriales, y más raras veces por abades de monasterios o miembros de la pequeña nobleza imperial, e incluso en casos muy excepcionales también por otras ciudades ${ }^{32}$. Algunas ciudades imperiales incluso descendieron a esta posición de ciudades mediatizadas, que es como se llamaba a las que no dependían directamente del titular del imperio, como consecuencia de la política de cesión en hipoteca de elementos del patrimonio imperial a cambio de préstamos o en premio a otros servicios, puesta en práctica con creciente frecuencia por los emperadores durante el siglo XIV, y que para muchas significó la pérdida definitiva de su condición de ciudades imperiales ${ }^{33}$. Y por supuesto estas numerosísimas ciudades mediatizadas tuvieron mucho más mermada su capacidad de autogobierno que las ciudades imperiales y libres, aunque en el caso de algunas de las principales ésta fue grande en los siglos bajomedievales, y sólo durante los siglos modernos sufrió importantes recortes, conforme se fueron consolidando los modelos absolutistas de gobierno en los principados territoriales.

\footnotetext{
${ }^{31}$ Sobre el papel reservado a las ciudades imperiales y libres en las instituciones del Imperio a fines de la Edad Media y comienzos de la Edad Moderna conviene consultar, Georg SCHMIDT, Der Städtetag in der Reichsverfassung. Eine Untersuchung zur Korporationspolitik der Freien und Reichsstädte in der ersten Hälfte des 16. Jahrhunderts, Stuttgart, 1984. Heinz ANGERMEIER, Die Reichsreform. 1410-1555. Die Staatsproblematik in Deutschland zwischen Mittelalter und Gegenwart, Múnich, 1984. Y Eberhard IsENMANN, Zur Frage der Reichsstandschaft der Freiund Reichsstädte, en "Stadtverfassung, Verfassungsstaat, Pressepolitik. Festschrift für Eberhard Naujoks", Sigmaringen, 1980, pp. 91-110. Para una valoración de la importancia política de las ciudades en el Imperio bajomedieval vid. W. ZORN, Die politische und soziale Bedeutung der Reichsstadtbürgertums im Spätmittelalter, en H. STOOB (Ed.) "Altständisches Bürgertum", vol 1, Darmstadt, 1978, pp. 336-360.

${ }^{32}$ El fenómeno de la imposición del señorio de unas ciudades sobre otras, que fue frecuente en Italia, no alcanzó apenas desarrollo en el Imperio al norte de los Alpes. Sobre los señoríos territoriales urbanos en este último ámbito vid. nuestro artículo, Los señoríos territoriales de las ciudades europeas bajomedievales. Análisis comparativo de los ejemplos castellano y alemán, "Hispania", 188 (1994), pp. 791-844.

${ }^{33}$ Vid. Götz LANDWEHR, Die Verpfïndung der deutschen Reichsstädte im Mittelalter, Colonia-Graz, 1967.
} 


\section{Las ciudades castellanas}

En la Corona de Castilla no tuvieron tanta importancia las ciudades de señorío episcopal como en el Imperio alemán, y, aunque en el siglo XII se dieron situaciones de conflicto en ciudades que tuvieron a obispos como señores entre éstos y sus vasallos ${ }^{34}$, éstas no se pueden equiparar por sus repercusiones históricas a las que se sucedieron en Alemania en los siglos XII y XIII, puesto que nunca alcanzaron un éxito completo, y ninguna ciudad castellana de señorío episcopal consiguió liberarse en época medieval de la relación de sometimiento y dependencia hacia sus señores los obispos, aunque las más pobladas y prósperas sí consiguiesen a veces amplios márgenes de autonomía ${ }^{35}$.

La mayoría de las ciudades de las regiones incorporadas por los reinos de Castilla y León a partir del siglo XI se mantuvieron de hecho en el realengo, mientras que los obispos, cabildos catedralicios y nobles laicos sólo consiguieron entonces por regla general para sus señoríos pequeños núcleos de carácter rural. Las ciudades realengas por su parte no fueron sometidas en estos siglos plenomedievales a una relación de dependencia señorial respecto a la persona del rey tan intensa como la que conocieron las

\footnotetext{
${ }^{34}$ Sobre estos movimientos sociales y políticos del siglo XII tratan entre otros Reyna PASTOR DE TOGNERI, Las primeras rebeliones burguesas en Castilla y León (siglo XII). Análisis histórico-social de una coyuntura, en "Conflictos sociales y estancamiento económico en la España Medieval", Ariel Barcelona, 1973. pp. 13-102. Y Jean GauTiER DalchÉ, Les mouvements urbains dans le nord-ouest de l'Espagne au XIIème. siècle. Influences étrangeres ou phenomènes originaux?, "Anexos a la Revista Hispania", 2 (1968), pp. 51-64.

${ }^{35}$ Un primer caso interesante nos lo proporciona Santiago de Compostela. Vid. S. LÓPEZ Alsina, La ciudad de Santiago de Compostela en la Alta Edad Media, Santiago, 1988. Y Carmen PALlARÉS ET ALII, La Tierra de Santiago, espacio de poder (siglos XII y XIII), en "Poder y sociedad en la Galicia Medieval", Santiago de Compostela, 1992, pp. 133-74. Para contrastar con el caso de otra ciudad más pequeña de la que también eran señores los arzobispos de Santiago, Pontevedra, vid. José Armas Castro, Pontevedra en los siglos XII a XV. Configuración y desarrollo de una villa marinera en la Galicia Medieval, Pontevedra, 1992. Otro ejemplo interesante nos los proporciona Palencia. Vid. R. CARANDE, El obispo, el concejo y los regidores de Palencia, 1355-1422. Aportación documental sobre el gobierno de una ciudad en la Edad Media, "Siete Estudios de Historia de España", Ariel. Barcelona. 1969, pp. 55-92. Y para fechas algo posteriores. A. EsTEBAN RECIO, Palencia a fines de la Edad Media. Una ciudad de señorio episcopal, Valladolid, 1989. Para contrastar con un caso de ciudad de señorío episcopal en la que el desarrollo de la conciencia política de la comunidad urbana fue menor que en Santiago o Palencia, vid. Adrián BlázQuez CARBAjosa, El señorío episcopal de Sigüenza, Guadalajara, 1988. Sobre la intervención de la monarquía en la vida política de las ciudades de señorío episcopal vid. José Manuel NIETO SORIA, La actitud de la monarquía respecto a las ciudades castellanas de señorío episcopal en la transición del siglo XIII al XIV, en "Simposio nacional sobre ciudades episcopales", Zaragoza, 1986, pp. 51-60.
} 
ciudades alemanas dependientes de los reyes y emperadores Salios y Staufer, ya se tratase de ciudades del patrimonio imperial o de ciudades del patrimonio familiar de estos linajes. En consecuencia la mayoría de las ciudades que se integraron en los reinos de Castilla y León en los siglos de máximo avance militar y repoblador desarrollaron inicialmente formas de organización sociopolítica distintas de las clásicas de corte feudoseñorial presentes en la misma época en la mayor parte de la Europa occidental, tanto en sus ámbitos rurales como urbanos. En ellas el proceso de consolidación de los órganos de autogobierno urbano no tuvo lugar a través de un conflicto más o menos violento con las instancia de dominio señorial, como ocurrió en las ciudades del Imperio en el siglo XII y durante la primera mitad del XIII, sino que en la mayor parte de las ciudades de realengo castellanas el progreso de la autonomía urbana frente al palatium, órgano representante del poder señorial del rey en las ciudades, se produjo por simple debilitamiento de éste, aunque la falta de documentación para la época no nos permite reconstruir en detalle las circunstancias en que dicho proceso tuvo lugar ${ }^{36}$. En cualquier caso no se dispone de noticias que permitan presumir que se llegasen a plantear conflictos de importancia entre estas dos instancias, a diferencia de lo que ocurrió en las ciudades de señorío eclesiástico durante el siglo XII.

De hecho la explicación más verosímil para dar cuenta del amplio grado de autonomía de que disfrutaron las ciudades de realengo castellanas hasta mediados del siglo XIII, es la que trata de poner en relación el fenómeno con la falta de medios de una monarquía que se se encontraba comprometida en una empresa de vertiginosa expansión territorial, que concluyó precisamente en la primera mitad del siglo XIII.

Y por ello no fue puramente casual que, una vez acabado el proceso de expansión territorial, cuando la monarquía castellana, reforzada además a partir de 1230 gracias a la unión definitiva de los reinos de Castilla y

\footnotetext{
${ }^{36}$ Para una visión global de este proceso Vid. Jean GAUTIER DaLCHÉ, Historia urbana de León y Castilla en la Edad Media (Siglos IX-XIII), Siglo XXI, Madrid, 1979, pp. 346 y ss. Sobre el "dominus villae", figura institucional en torno a la que se estructuraba el "palatium" vid. Nilda Guglielmi, El "dominus villae" en Castilla y León, "Cuadernos de Historia de España", 19 (1953), pp. 55-103. Sus facultades al parecer fueron débiles en materia judicial. En algún fuero se prohibe su presencia en la curia de alcaldes, para evitar coacciones en la administración de la justicia local. Cabe pensar en un delegado regio con predominantes cometidos administrativos, militares y de representación y salvaguarda de los intereses regios en el ámbito local. A partir de fines del XII y comienzos del XIII comienzan a escasear las referencias a este delegado regio. Eran siempre infanzones.
} 
León, pasó a concentrarse en potenciar sus instrumentos de intervención sobre el reino, las ciudades comenzasen a perder cuotas de autonomía. Y el nuevo signo de los tiempos ya se puso de manifiesto en la forma de llevarse a cabo la estructuración institucional de las tierras andaluzas, puesto que en la mayoría de las ciudades allí conquistadas a los musulmanes no se concedió a los repobladores cuotas de autogobierno tan amplias como las que todavía seguían disfrutando las ciudades al norte de Despeñaperros ${ }^{37}$.

Así por ejemplo, en las ciudades andaluzas que fueron repobladas a fuero de Toledo no se le permitió a la población local intervenir directamente en el nombramiento de los oficiales de la justicia, reservándose esta atribución al rey, mientras que en las pocas que se repoblaron a fuero de Cuenca, como por ejemplo Úbeda o Baeza, esta intervención regia no se contempló inicialmente ${ }^{38}$.

En cualquier caso ya durante los reinados de Alfonso X y Sancho IV se comenzó a recurrir con relativa frecuencia al envío de alcaldes del rey a muchas ciudades del reino, fuera de Andalucía. Y de hecho uno de los objetivos de Alfonso $\mathrm{X}$ al tratar de imponer el Fuero Real fue el de acabar con la institución de los alcaldes foreros, que este texto legal pretendía sustituir por alcaldes de nombramiento regio, semejantes a los que ya actuaban en las ciudades andaluzas repobladas a fuero de Toledo. De esta manera el objetivo de uniformización del sistema jurídico y superación del particularismo de los fueros, iba unido a un propósito de centralizar los aparatos de poder político en torno al rey y su corte. Y por ello todas las ciudades que habían disfrutado de amplias cotas de autogobierno y habían podido elegir libremente a sus propios oficiales de la justicia, incluidas las andaluzas repobladas a fuero de Cuenca, como Úbeda o Baeza, reaccionaron fuertemente en contra de estos proyectos.

\footnotetext{
${ }^{37}$ Sólo disfrutaron de cierta capacidad de autogobierno las ciudades andaluzas que recibieron fuero de Cuenca. como por ejemplo Baeza o Úbeda. Para la historia institucional de las ciudades andaluzas vid. M. GonZÁlez JimÉnEz. Los municipios andaluces en la Baja Edad Media. "Archivo Hispalense" 210 (1986), pp. 63-83. De este mismo autor Ciudades y concejos andaluces en la Edad Media: Gobierno urbano. "Concejos y ciudades en la Edad Media hispánica. II Congreso de Estudios Medievales". Fundación Sánchez-Albornoz, León. 1990, pp 239-260. Y. aunque de alcance más general. por referirse a todas las ciudades castellanas, Las Cortes de Castilla y León y la organización municipal, en "Las Cortes de Castilla y León en la Edad Media", Cortes de Castilla y León, 1988, pp. 351-375.

${ }^{38}$ Entre otras ciudades importantes fueron repobladas a fuero de Toledo las de Sevilla, Córdoba, Jaén, Murcia. Algeciras. Ecija. Jerez. Niebla, y tal vez también Carmona. Durante los años de la minoría de Alfonso XI tuvo lugar un intento en Córdoba de convertir las alcaldías en oficios de nombramiento concejil.
} 
Como consecuencia Alfonso X tuvo que dar marcha atrás en más de una ocasión, para no poner en su contra a los concejos, en momentos en que no podía prescindir de su colaboración política y militar, y así ocurrió por ejemplo por primera en $\mathbf{1 2 6 5}$, cuando ante el peligro de un ataque de los benimerines, renunció a su propósito de imponer el Espéculo, y confirmó los fueros concejiles. De nuevo en 1272 la resistencia conjunta de nobleza y concejos, que adoptó formas mucho más drásticas que en momentos anteriores, le forzó a tener que reconocer la vigencia de los fueros locales, renunciando al propósito de imponer el Fuero Real. Y por fin sus reiterados intentos de coartar las libertades de los concejos castellanos, recogidas en sus fueros, fueron los que más contribuyeron a alimentar una creciente oposición política de la población de estos concejos, o al menos de sus élites dirigentes, hacia la persona de este monarca, determinando que a comienzos de la década de los 80, al radicalizarse el enfrentamiento del infante Sancho contra su padre, la mayoría de las ciudades castellanas tomasen abiertamente partido por el primero, con la única excepción significativa de Sevilla.

No hay duda por tanto de que en la segunda mitad del siglo XIII las ciudades castellanas manifestaron una decidida disposición a resistir activamente los intentos de la monarquía de cercenar su capacidad de autogobierno, aunque su potencial político no era tan grande como para por sí solas poder imponer al monarca sus criterios, de manera que si en algún momento llegaron a hacer peligrar la supervivencia política de Alfonso X fue gracias a que sus fuerzas confluyeron con las de la nobleza.

Por lo demás el interés de la monarquía por incrementar su capacidad de intervención política en las ciudades de realengo se demostró persistente, de manera que después de muerto Alfonso X, su hijo Sancho IV, una vez asentado en el trono, se mostró menos comprensivo hacia las reivindicaciones de las ciudades que cuando había necesitado el apoyo de éstas para luchar contra su padre, como lo demuestra su decisión de suprimir la Hermandad, y la reanudación por su parte de la práctica de interferir en el nombramiento de la justicia en los concejos. No obstante también él tuvo que dar marcha atrás en algunos momentos en sus proyectos, y así lo demuestra el que por ejemplo en 1286 ordenase devolver a los concejos las alcaldías de que había dispuesto en años anteriores ${ }^{39}$.

\footnotetext{
${ }^{39}$ Vid. M. GonzÁlez JimÉnez, Las Cortes de Castilla y León, p. 355.
} 
Por consiguiente cuando acabó el siglo XIII la mayor parte de las ciudades castellanas, con la única excepción significativa de las andaluzas repobladas a fuero de Toledo, continuaban manteniendo su tradicional sistema de autogobierno, garantizado por los fueros y las figuras institucionales de los alcaldes foreros y los concejos abiertos. Pero habían entrado ya en una fase claramente defensiva, y aunque no dejaron de dar muestras de su interés por conservar los privilegios adquiridos, en última instancia no lo lograron porque los grupos gobernantes urbanos terminaron renunciando al objetivo del autogobierno a cambio de que la monarquía les garantizase su consolidación como oligarquías privilegiadas. Y este proceso, que ya se estuvo gestando durante toda la segunda mitad del siglo XIII, llegó a su culminación en la primera mitad del siglo XIV, después de haber fracasado los proyectos alternativos que se estuvieron ensayando durante las minorías de Fernando IV y Alfonso XI, que de haber prosperado tal vez hubiesen llevado en primer lugar a que en Castilla las ciudades se consolidasen como una fuerza política de primera fila, con voz y voto en los órganos de gobierno central de la monarquía, y en segundo lugar a que en su organización sociopolítica interna estas mismas ciudades no adoptasen unos modelos de tan marcado carácter oligárquico y tan fuerte impronta nobiliaria como los que se terminaron imponiendo en ellas.

\section{Novedades en la organización institucional de las ciudades durante el siglo XIII}

Los fenómenos del auge de las "libertades urbanas" en Alemania y su progresiva decadencia en Castilla a partir de mediados del siglo XIII comenzaron a tener ya en este siglo importantes traducciones en el plano institucional, más en el primer ámbito que en el segundo, puesto que para Alemania el siglo XIII representó el período clave de reestructuración de los órganos de gobierno urbanos, al ser entonces cuando se produjo el proceso de surgimiento y consolidación de la institución del consejo ciudadano (Rat), pieza clave del sistema de autogobierno urbano alemán, mientras que para Castilla fue la primera mitad del siglo XIV la que representó el período de principales cambios institucionales en el régimen de gobierno de sus ciudades, aunque ya tuvo lugar un interesante preludio en el siglo XIII, al regularse el régimen de gobierno de las recién conquistadas ciudades andaluzas. Y ni que decir tiene que el Rat de las ciudades alemanas y el 
regimiento de las castellanas fueron instituciones de signo completamente contrapuesto.

El Rat ha sido considerado como el equivalente al norte de los Alpes del consulado de las ciudades italianas, por tratarse de un órgano de gobierno colegiado que surge de la propia comunidad política urbana, y que asume funciones de autogobierno y también la tarea de impartir justicia. Las diferencias entre ambas instituciones son, sin embargo, también notables, pero a pesar de ello muchos autores han defendido la tesis de que la institución del consulado italiano sirvió directamente como modelo a las primeras ciudades alemanas que adoptaron el Rat en sus constituciones políticas, aunque unas y otras corrientes interpretativas discrepan sobre el modo en que estas ciudades alemanas entraron en contacto con la realidad institucional italiana, para a continuación proponerse su imitación. Según algunos autores, como por ejemplo Planitz, fue clave la actuación del emperador Staufer Enrique VI, que habría intervenido personalmente en la introducción de la institución del Rat en algunas ciudades alemanas con el propósito de contrapesar la tendencia a la consolidación de oligarquías en éstas, proponiendo el ejemplo de Spira, donde el emperador compartía el señorío con el obispo ${ }^{40}$.

Otros autores niegan validez a esta hipótesis, y defienden otra que sostiene que la institución del Rat llegó desde Italia a las ciudades alemanas a través del reino de Borgoña, y se fue expandiendo desde Basilea a lo largo del valle del $\mathrm{Rhin}^{41}$. No obstante se ha discutido mucho sobre la fecha en que se puede constatar la existencia del primer Rat en Basilea, y en la actualidad se tiende a retrasarla a las primeras décadas del siglo XIII ${ }^{42}, \mathrm{y}$ por otra parte en ciudades alejadas del valle del Rhin, como por ejemplo Lübeck, la institución del Rat aparece constatada muy tempranamente, concretamente en $1201^{43}$, por lo que esta teoría también tiene muchos detractores.

\footnotetext{
${ }^{40}$ Vid. H. Planitz, op. cit. pp. 300-301. En 1198 Enrique VI concede un privilegio a la ciudad de Spira, en el que se constata que él ha encomendado la administración de la ciudad a un colegio constituido por 12 ciudadanos que se renuevan anualmente. 101 y ss.

${ }^{41}$ Vid. Horst RABE, Der Rat der niederschwäbischen Reichsstädte, Colonia-Graz, 1966, pp.

${ }^{42}$ Vid. Reinhard PATEMANN, op. cit. pp. 449 y ss.

${ }^{43}$ Vid. Fritz RoERIG, Lübeck und der Ursprung der Ratsverfassung, en "Hansische Beiträge zur deutschen Wirtschaftsgeschichte", Breslau, 1928.
} 
En cualquier caso el hecho sobre el que más interesa llamar la atención es que la adopción de la institución del Rat se produce con considerable retraso en las ciudades alemanas con respecto a las italianas, e incluso a las de la Francia del Sur ${ }^{44}$, y este hecho demuestra cómo la impronta señorial fue en las primeras mucho más fuerte que en estas últimas. Por lo demás la aparición del Rat en las ciudades alemanas ofrece sensibles diferencias cronológicas entre unas y otras, pudiéndose comprobar, salvando casos excepcionales como el de Lübeck ${ }^{45}$, que la institución se consolida mucho más tempranamente en las grandes ciudades de señorío episcopal, y con un evidente retraso respecto a éstas en las de señorío regio, en la mayoría de las cuales hubo que esperar hasta el Interregno para que se iniciase el proceso de difusión de esta institución, que luego alcanzó en ellas un profundo arraigo ${ }^{46}$.

Y las mismas diferencias cronológicas se advierten al constatar la aparición de la figura del Bürgermeister, pieza clave del entramado institucional de las ciudades alemanas, que contrasta con la del corregidor en Castilla o la del podestá en las ciudades italianas, por tratarse de una magistratura urbana desempeñada por un vecino de la ciudad, generalmente designado por procedimiento de elección en el seno de la comunidad política local $^{47}$. En concreto por lo que se refiere a las ciudades de señorío episcopal el Bürgermeister ya aparece constatado en Worms hacia 1220, y en Spira en 1230, mientras que en las de señorío regio su aparición es mucho más tardía, como lo demuestra el que entre las ciudades suabas las pioneras

\footnotetext{
${ }^{44}$ En éstas el consulado ya había alcanzado gran difusión en la primera mitad del XII, constatándose en Marsella en 1128 y en Narbona en 1148.

${ }^{45} \mathrm{La}$ ciudad de Lübeck fue pionera entre las ciudades imperiales en la obtención de privilegios políticos, que redujeron considerablemente la capacidad de intervención señorial en ella. En 1226 Federico II le concedió un privilegio reconociéndola como ciudad imperial libre (Reichsfreiheitsprivileg). Vid. Georg Wilhelm VON BRANDT, art. cit.

${ }^{46}$ Vid. Horst RABE, Frühe Stadien der Ratsverfassung in den Reichslandstädten bzw. Reichsstädten Oberdeutschlands, en B. DIESTELKAMP (ed.), "Beiträge zum Spätmittelalterlichen Städtewesen", Colonia-Viena, 1982, pp. 1-17. Y también Der Rat der niederschwäbischen Reichsstädte, Colonia-Graz, 1966.

${ }^{47} \mathrm{El}$ corregidor castellano por el contrario era de designación regia. El podestá italiano, aunque se elegía por la comunidad política local, tenía que ser siempre un extranjero. Posteriormente también para el oficio de capitano del popolo se designaron extranjeros. J.K. HYDE, Society and Politics in Medieval Italy. The evolution of the Civic Life 1000-1350, Londres, 1973, pp. 101 y ss. y 113 y ss. Con frecuencia los podestá degeneraron en tiranos, y cuando en las ciudades alemanas empiezan a aparecer los burgomaestres en las italianas ya lo hacen los primeros déspotas.
} 
fuesen las de Rottweil, donde la figura se constata en 1283, y Ulm, donde se menciona por primera vez en $1292^{48}$.

Durante el siglo XIII las ciudades castellanas no experimentaron transformaciones institucionales de tanta trascendencia como las que tuvieron lugar en las ciudades del Imperio, con la excepción de Andalucía por razones históricas concretas, relacionadas con el fenómeno de la conquista y repoblación. Y hubo que esperar al siglo XIV para que se impusiese la gran reforma institucional que supuso la instauración del regimiento en las principales ciudades del reino. Esta institución, sin embargo, presentó un enorme contraste con el Rat de las ciudades alemanas, pues no en vano en este último los consejeros eran elegidos por la propia sociedad política urbana, y habitualmente tenían unos períodos de mandato limitados, en muchos casos anuales, mientras que en las principales ciudades de Castilla los regidores fueron oficiales nombrados por el rey, casi siempre con carácter vitalicio.

\section{TRANSFORMACIONES EN LA SOCIEDAD URBANA Y PRESENCIA DE GRUPOS PRIVILEGIADOS EN LAS CIUDADES}

\section{Los ministeriales en las estructuras sociopolíticas de las ciudades alemanas del siglo XIII y el problema de la nobleza urbana.}

El panorama social de las ciudades alemanas ofrecía en los siglos XI al XIII como rasgo más original la presencia en su seno de los ministeriales, quienes conformaban un estamento marcado por la condición servil, que conllevaba para ellos importantes restricciones en la libertad de disposición de sus bienes y personas. A pesar, sin embargo, de este origen servil estos ministeriales llegaron a alcanzar una posición sociopolítica de notable preeminencia tanto en las ciudades como en los territorios rurales, superior sin duda a la de otros grupos sociales a los que formalmente se les reconocía la condición libre, como por ejemplo el de los mercaderes. Y esta circunstancia fue la que permitió que a partir de los siglos XII y XIII se pusiese en marcha un decidido proceso de asimilación de este estamento a la baja nobleza a través de la caballería, facilitado decisivamente por la adquisición

\footnotetext{
${ }^{48}$ H. RABE, Der Rat der niederschwäbischen, pp. 226-7.
} 
del derecho de recibir de sus señores feudos, que hasta entonces había estado reservado exclusivamente a los nobles de origen libre ${ }^{49}$.

La investigación historiográfica, sin embargo, hasta fechas muy recientes sólo había considerado posible este ascenso de los ministeriales a la baja nobleza en los ámbitos rurales, partiendo del presupuesto de que en las ciudades los ministeriales representaban un elemento extraño condenado a la desaparición a partir del momento en que éstas alcanzaban la plena autonomía frente a sus señores y se consolidaban desde el punto de vista sociopolítico como comunidades juradas inspiradas por principios de carácter consociativo, que aseguraban a todos sus miembros los mismos derechos y obligaciones $^{50}$.

Se ha podido comprobar, sin embargo, que en muchas ciudades los ministeriales, lejos de abandonarlas conforme éstas iban liberándose del dominio señorial, consiguieron integrarse en sus grupos dominantes y asegurarse incluso en su seno las posiciones de mayor influencia, y a veces también el disfrute de determinados privilegios. En concreto K. Schulz ha dedicado muchos trabajos a demostrar estas tesis, centrándose preferentemente en el análisis de ciudades que habían sido de señorío episcopal y en las que había adquirido notable desarrollo el grupo de los "ministeriales ecclesiae" como estamento privilegiado ${ }^{51}$. Y el argumento central de todos estos trabajos ha consistido siempre en poner de manifiesto que en todas estas ciudades las familias descendientes de ministeriales mantuvieron durante el siglo XIII una posición hegemónica gracias al disfrute de privilegios estamentales, entre los que destacaba por sus notables repercusiones en el terreno sociopolítico el que les capacitaba para recibir feudos

\footnotetext{
${ }^{49}$ Vid. J. FLECKENSTEIn, Die Entstehung des niederen Adels und das Rittertum, en J. FLECKENSTEIN (Ed.) "Herrschaft und Stand. Untersuchungen zur Sozialgeschichte im 13 Jahrhundert", Göttingen, 1977, pp. 17-39. Y K. BoSL, Die adelige Unfreiheit, en F.L. WAGNER, "Ministerialität im Pfalzer Raum", Spira, 1975, pp. 9-19.

${ }^{50}$ Uno de los principales defensores de esta tesis fue H. PLANITZ, Die deutsche Stadt des Mittelalters. Von der Römerzeit bis zu den Zunftkämpfen, Graz-Colonia, 1954.

${ }^{51}$ Sobre Colonia trata su artículo Richerzeche, Meliorat und Ministerialität in Köln, en H. STEHKÄMPER, (Ed.), "Köln, Das Reich und Europa", Colonia, 1971, pp. 149-172. Sobre Tréveris su tesis doctoral, Ministerialität und Bürgertum in Trier. Untersuchungen zur rechtlichen und sozialen Gliederung der Trierer Bürgerschaft vom ausgehenden 11. bis zum Ende des 14. Jahrhunderts, Bonn, 1968. Sobre Worms, Die Ministerialität als problem der Stadtgeschichte. Einige allgemeine Bemerkungen, erläutert am Beispiel der Stadt Worms, "Rheinische Vierteljahrsblätter", 32 (1968), pp. 184-219.
} 


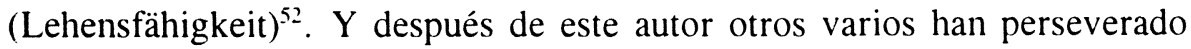
en esta línea argumental, ampliando el campo de observación a otras ciudades de señorío episcopal, como Estrasburgo ${ }^{53}$, y sobre todo también a ciudades de señorío regio como Dortmund ${ }^{54}$, Nürnberg, Altenburg y Frankfurt-am-Main 55 .

No obstante, los autores fieles a la tradicional línea interpretativa, sin negar la evidencia del predominio de familias de origen ministerial en los grupos dirigentes de muchas ciudades alemanas, han persistido en el punto de vista que sostiene que este ëstamento como tal representaba un elemento extraño a las estructuras sociopolíticas urbanas del Imperio alemán, de forma que, según ellos, todos aquellos individuos de origen ministerial que terminaron integrándose en la vida urbana lo conseguirían gracias a haberse asimilado al estamento burgués, que tendría su origen en las comunidades juradas de mercaderes libres, en las que luego se fueron integrando otros

\footnotetext{
${ }^{52}$ Este autor en todas sus obras insiste en recordar que entre la población de las ciudades la capacidad de obtener feudos fue una prerrogativa reservada inicialmente sólo para los ministeriales, y en contrapartida resta importancia a las concesiones de privilegios de Lehensfähigkeit al conjunto de los vecinos de determinadas ciudades por parte de los reyes. al considerar que se trató de un fenómeno tardio. que no amenazó la posición privilegiada que ya habian consolidado los ministeriales. Corrobora esta tesis de que la mayoría de los privilegios de Lehensfähigkeit concedidos por los reyes a ciudades para el conjunto de sus vecinos tenían un alcance limitado y no permitian en este punto una equiparación total entre individuos de origen burgués y miembros de la pequeña nobleza, ya fuesen de origen libre o ministerial, $\mathrm{H}$ LIEBERICH. Rittermässigkeit und bürgerliche Gleichheit. Anmerkungen zur gesellschaftlichen Stellung des Bürgers im Mittelalter. "Festschrift für Hermann Krause", Colonia-Viena, 1975. pp. 79-80. El monarca que comenzó a conceder estos privilegios a las ciudades fue Rodolfo I, quien según Th. MARTIN perseguiría así el objetivo de favorecer la fusión sociopolítica entre los caballeros con residencia urbana y los burgueses. Vid. Die Städtepolitik Rudolfs ion Habshurg. Göttingen. 1976. pp. 142-3.

${ }^{53}$ Helga MOSBACHER. Kammerhandwerk, Ministerialität und Bürgertum in Strassburg. Studien zur Zusammensetzung und Enwicklung des Patriziats im 13. Jahrhundert. "Zeitschrift für die Geschichte des Oberrheins, 119 (1971). pp. 35-173.

${ }^{54}$ Dietrich THIER, Melius Hereditati: Untersuchungen zar Dortmunder Führungsschicht im 13. und 14. Jahrhundert. Bochum, 1987.

${ }^{55}$ Sobre Estrasburgo vid. H. MOSBACHER. Kammerhandwerk. También presenta interés la monografía que dedica a Ratisbona K. BOSL. Die Soziclstruktur der mittelalterlichen Residenzund Fernhandelsstadt Regenshurg. Die Entwicklung ihres Bürgertums vom 9.-14. Jalurhundert. en Th. MAYER. "Untersuchungen zur gesellschaftlichen Struktur der mittelalterlichen Städte in Europa". Constanza-Stuttgart. 1966. pp. 93-213. Y sobre Maguncia L. Falck Mainzer Ministerialität, en F.L. WAGNER, op. cit. pp. 44-59. A ciudades de señorío regio dedican su atención por ejemplo A. ScHLUNk. Stadt olme Bürger? Eine Untersuchung ïber die Führunsschichten der Städte Nürnberg, Altenburg und Frankfurt um die Mitte des 13. Jahrhumderts, en U. BERTMANN. F. IRSIGLER. y J. SCHNEIDER (Eds.) "Hochfinanz. Wirtschftsräume. Innovationen. Festschrift für Wolfgang von Stromer". Tréveris, 1987, vol I. Y sobre Goslar vid. W. PETKE, ob. cit.
} 
sectores conforme avanzó el proceso de uniformización jurídica de la población urbana ${ }^{56}$. Y estas reticencias a admitir que los ministeriales consiguiesen reservarse un puesto en las estructuras sociopolíticas urbanas que les garantizase la preservación durante un largo tiempo de sus privilegios estamentales, han llevado a algunos autores a negar incluso el origen ministerial de determinados individuos o grupos que en distintas ciudades alemanas aparecen en el siglo XIII expresamente identificados como caballeros $^{57}$.

Hoy por hoy, sin embargo, la tesis que va consiguiendo imponerse entre los historiadores alemanes es la que defiende que, en contra de lo que en su momento sostuvo Ennen, y con ella toda una fecunda corriente historiográfica, en las estructuras sociopolíticas de las ciudades alemanas durante los siglos plenomedievales los elementos nobles, de origen preferentemente ministerial ${ }^{58}$, llegaron a desempeñar un papel muy destacado, que se explica en gran medida por el propio origen señorial de estas ciudades.

Ciertamente hubo ciudades en Alemania que manifestaron una cierta intransigencia a la hora de admitir en su seno elementos nobles formalmente

56 Defiende este punto de vista. siguiendo planteamientos ya presentes en la obra de Planitz. J. Fleckenstein. Die Problematik ron Ministerialität und Stadt im Spiegel Freiburger und Strassburger Quellen. en E. MASCHKE y J. SYDOw (Eds.). Stadt and Ministerialität, Stuttgart. 1973. pp. 1-15. Y Ministerialität und Stadtherrschaft. Ein Beitrag zu ihrem Verhältmis am Beispiel von Hildesheim und Brannschweig. en "Festschrift für Helmut Beumann zum 65 Geburtstag". 1977, pp. 349-364.

${ }^{57}$ Así procede por ejemplo $S$. WILKE al referirse a los caballeros de Goslar del siglo XIII, en Das Goslarer Reichsgebiet und seine Beziehungen zu den territorialen Nachbargewalten, Max Planck Institut, Göttingen, 1971. Una critica a los planteamientos de WILKE en W. PETKE. Pfalzstadt und Reichsministerialität. Üher einen neuen Beitrag aur Reichsgut- und Pfalzenforschung. "Blätter für deutsche Landesgeschichte" (1973). pp. 300 y ss. También Ph. Doli.INGER muestra reticencias a buscar el origen de los patriciados nobles de las ciudades altorrenanas del siglo XIII en los ministeriales. Vid. Das Patriziat der oberrheinischen Städte und seine inneren Kämpfe in der ersten Hälfte des 14. Jahrhunderts, en H. STOOB (Ed.). Altständisches Bürgertum, Darmstadt, 1978, vol. II. pp. 198-9. Critica su punto de vista sobre Estrasburgo H. MOSBACHER, Kammerhandwerk, Ministerialität und Bürgertum in Strassburg. Studien zur Zusammensetzung und Entwicklung des Patriziats im 13. Jahrhundert, "Zeitschrift für die Geschichte des Oberrherins" 119 (1971), pp. 158 y ss.

${ }^{58} \mathrm{~K}$. SCHUlz insiste en que no todos los miembros de las oligarquias urbanas de origen ministerial pueden ser considerados representantes de la nobleza urbana. sino sólo aquéllos que aparecen expresamente identificados como caballeros (Ritter). En Nobiltì urbana e borghesia, specialmente nelle città della Germania meridionale (secolo XV). en R. ELZE y G. FASOLI, "Aristocrazia cittadina e ceti popolari nel tardo Medioevo in Italia e in Germania". Bolonia. 1984, pp. 223-53. 
privilegiados, como fue el caso de Hamburgo y Lübeck ${ }^{59}$, pero en el siglo XIII éstas representaban una minoría. En contrapartida también eran minoritarias las ciudades en las que se consolidaron patriciados nobles perfectamente diferenciados, del tipo de los analizados por Dollinger en las ciudades renanas ${ }^{60}$, pero en la mayoría de las ciudades alemanas coexistieron en esta época de una forma bastante fluida elementos nobles con otros que no lo eran.

La imbricación de las ciudades alemanas en sus orígenes en las estructuras políticas feudoseñoriales conllevó para sus propias estructuras sociopolíticas en sus primeras fases de desarrollo como comunidades autónomas la presencia entre sus sectores dirigentes de grupos privilegiados, que aunque en su mayor parte eran de origen servil, consiguieron a lo largo del siglo XIII incorporarse al estamento de la baja nobleza a través de la caballería y de la obtención del privilegio de poder recibir feudos (Lehensfähigkeit). En algunas ciudades estos grupos privilegiados se consolidaron como auténticos estamentos nobiliarios, diferenciados frente a un sector burgués o ciudadano de la oligarquía, y en la mayoría simplemente se dio una coexistencia en el seno de los grupos oligárquicos de personas con el rango de caballeros con otras que no lo tenían. En cualquier caso la presencia de estos elementos nobles representó ante todo una herencia del pasado, y múltiples factores llevaron pronto a su total erradicación, de manera que ya a comienzos del siglo XV representaban casos excepcionales los de las ciudades en las que seguía existiendo un grupo noble diferenciado del resto de la población.

En concreto una circunstancia que favoreció la progresiva desaparición de elementos nobles de las ciudades alemanas en el transcurso del siglo XIV fue que la posición de las familias de origen ministerial que permanecieron en las ciudades cuando éstas consolidaron su plena autonomía frente a sus señores estuvo sometida a fuertes contradicciones, por cuanto muchos

\footnotetext{
${ }^{59}$ Sobre Hamburgo Vid. Otto BRUNNER, Hamburg und Wien. Versuch eines sozialgeschichtlichen Vergleichs, en "Neue Wege der Verfassungs- und Sozialgeschichte", Göttingen, 1968 , p. 326. El derecho urbano de 1270 prohibía que los caballeros tuviesen residencia en Hamburgo, y por consiguiente los ciudadanos de Hamburgo nunca pudieron recibir feudos. Este autor considera que fue un caso excepcional, incluso en la Alemania del Norte, puesto que hasta en la propia ciudad de Lübeck fue frecuente que ciudadanos adquiriesen bienes de caballeros de su entorno. Para demostrar, no obstante, la orientación antinobiliaria de Lübeck Edith ENNEN recuerda que en esta ciudad estaba prohibido a las hijas de los ciudadanos casar con nobles. Vid. Frühgeschichte der europäischen Stadt, Bonn, 1977. pp. 42-66.

${ }^{60}$ Vid. P. DOllinger, Das Patriziat.
} 
de sus miembros continuaron manteniendo vinculaciones de carácter feudovasallático con estos últimos, y las obligaciones que de esta relación se derivaban para ellos entraban frecuentemente en contradicción con las que habían contraído hacia el sistema urbano en el que estaban integrados. Y por esta razón en determinadas coyunturas políticas ciertos sectores de las oligarquías urbanas con marcadas inclinaciones pronobiliarias rompieron los lazos de fidelidad hacia el sistema urbano y optaron por integrarse de forma definitiva en las corporaciones de la pequeña nobleza rural $^{61}$. Pero este fenómeno fue más propio de los siglos XIV, XV y XVI que del propio siglo XIII, cuando todavía las relaciones entre los descendientes de ministeriales residentes en el campo y los integrados en comunidades urbanas eran relativamente fluidas, y resultaba hasta cierto punto compatible mantener una doble fidelidad a los poderes feudales y al sistema político urbano ${ }^{62}$. Sólo los ministeriales de más alto rango encontraron dificultades desde el primer momento, ya en pleno siglo XIII, para integrarse en las nuevas comunidades urbanas liberadas de la tutela señorial, y optaron por consiguiente por trasladarse al campo, como ocurrió por ejemplo en Estrasburgo en $1263^{63}$, o en la ciudad imperial de Frankfurt-am-Main a comienzos del reinado de Rodolfo $\mathrm{I}^{64}$, no pudiéndose hablar en ninguno de estos casos de defección

\footnotetext{
${ }^{61}$ Refïriéndose a situaciones planteadas en el siglo XIV ilustra muy bien esta problemática M. Alioth, Gruppen an der Macht. Zünfte und Patriziat in Strassburg im 14. und 15. Jahrhundert. Untersuchungen zur Verfassung, Wirtschaftsgefüge und Sozialstruktur, BasileaFrankfurt, 1988, vol. 1, pp. 222 y ss.

${ }^{62}$ En su análisis del caso de Maguncia L. FALCK demuestra que los descendientes de ministeriales de los arzobispos maguntinos dieron cuerpo tanto al patriciado urbano de Maguncia como a la pequeña nobleza de su entorno rural, dándose relaciones fluidas entre ambos grupos hasta el siglo XIV, cuando los linajes nobles asentados en el campo tendieron a cerrarse frente al patriciado urbano, que pasó a ser considerado de rango inferior. Vid. Mainzer...

${ }^{63} 1263$ marca en esta ciudad el momento de la consecución definitiva de la autonomía urbana frente al poder episcopal. Según la tesis clásica en aquel año todos los ministeriales habrían abandonado la ciudad, siguiendo a su señor el obispo. Vid. J. FLECKENSTEIN, Die Problematik. H. MOSBACHER ha tratado de demostrar, sin embargo, que sólo fueron los ministeriales de más alto rango los que entonces marcharon, permaneciendo en Estrasburgo el resto de los ministeriales integrados en la comunidad urbana, los cuales a partir de entonces pasaron a adoptar el título de milites, hasta aquel momento reservado a los ministeriales mayores. Vid. su artículo Kammerhandwerk.

${ }^{64}$ Seis ministeriales imperiales construyeron el castillo de Rödelheim en las cercanías de Frakfurt, poniéndose al servicio del monarca Rodolfo I. A raíz de ello sus nombres desaparecieron de las listas de testigos de los documentos de la ciudad de Frankfurt, y ya no volvieron a aparecer en éstas individuos identificados como milites. Vid. F. SCHWIND, Die Landvogtei in der Wetterau, Marburg, 1972, p. 110. Los conflictos entre caballeros y ciudadanos fueron frecuentes en las ciudades de señorío regio del Wetterau durante el reinado de Rodolfo I, y en algunos casos se prolongaron hasta bien entrado el siglo XIV. Damos cuenta
} 
hacia el sistema político urbano puesto que quienes abandonaban la ciudad no habían estado integrados nunca en él.

Un hecho que en este contexto no conviene olvidar es que en Alemania la pequeña nobleza, que se consolidó en el siglo XIII como grupo social al que se incorporaron masivamente los ministeriales, fue desarrollando en los siglos bajomedievales unas marcadas tendencias exclusivistas frente a los sectores en auge de las ciudades, a los que insistió en presentar como inferiores en rango. Y uno de los procedimientos de los que se sirvió para marcar esta frontera estamental fue cerrar a la población de la ciudades el acceso a los cabildos catedralicios que tenían su sede precisamente en ellas, pero que se terminaron consolidando en la mayoría de los casos como unos elementos totalmente extraños al sistema político urbano, que entraron muy frecuentemente en conflicto con él.

Un ejemplo muy significativo lo encontramos ya en el siglo XIII en la ciudad de Worms, donde en 1281 el cabildo de la catedral decidió no admitir en adelante a ningún individuo de origen ciudadano, reservando las dignidades y canonjías para familias nobles y de caballeros. En aquellos momentos había todavía de hecho caballeros avecindados en la ciudad, que eran descendientes de ministeriales, pero actitudes como la adoptada por el cabildo necesariamente debieron despertar animosidad hacia ellos entre el resto de la población, que no vería con buenos ojos su posición privilegiada. $\mathrm{Y}$ de hecho en los años siguientes proliferaron los conflictos entre los ciudadanos de un lado, y los caballeros y el clero de otro, que finalmente desembocaron en el abandono de la ciudad por parte de los caballeros a principios del siglo $\mathrm{XIV}^{\mathrm{65}}$.

Otro ejemplo bien conocido de discriminación hacia el estamento ciudadano por parte del estamento noble nos lo proporciona Augsburgo, donde en 1322 el cabildo aprobó un estatuto que prohibió el acceso al mismo a todos cuantos no fuesen de origen noble, y muy en particular a los miembros de las familias avecindadas en esta ciudad, entre las que llegó a haber algunas enormemente acaudaladas, como las ya célebres de los Welser

\footnotetext{
de algunos de ellos desde la perspectiva de la historia de los castillos imperiales emplazados en ciudades alemanas en El papel de los castillos en las ciudades de señorio regio en Castilla y en el Imperio alemán. Análisis comparativo. Siglos XII-XV, "Estudios de historia y de arqueología medievales", XI (1996), pp. 85-130.

${ }^{65}$ Vid. Th. ZOTZ, Bischöfliche Herrschaft, Adel, Ministerialität und Bürgertum in Stadt und Bistum Worms (11.-14. Jahrhundert), en J. FLECKENSTEIN (Ed.) Herrschaft und Stand... pp. 92-136. En especial p. 131.
} 
$\mathrm{y}$ los Fugger ${ }^{66}$. Los ciudadanos de Augsburgo nunca aceptaron de buen grado que se les discriminase de esta forma en su propia ciudad, y por ello las instituciones de gobierno urbano iniciaron en 1475 un pleito en la Curia romana para forzar al cápítulo catedral a aceptar en su seno a miembros del estamento ciudadano, que se prolongó hasta 1492. El cabildo obtuvo entonces el apoyo decidido de la nobleza suaba y de otros obispos y cabildos de la región, mientras que a la ciudad la apoyó el propio rey, muy necesitado del dinero que le prestaban algunos de sus vecinos más acaudalados. Pero a pesar de ello el cabildo consiguió entonces imponer su criterio, y de nuevo en 1511, cuando un miembro de la familia Welser obtuvo en Roma un canonicato para la catedral de Augsburgo, y fue forzado por el cabildo a renunciar al mismo. Y el mismo resultado tuvieron todos los intentos de romper este riguroso exclusivismo estamental habidos hasta el siglo XVIII ${ }^{67}$.

Situaciones semejantes se vivieron en la mayoría de los principales cabildos catedrales alemanes, como ilustran los casos de Spira ${ }^{68}$, Maguncia $^{69}$, Colonia, Tréveris y Estrasburgo ${ }^{70}$. Por supuesto también hubo algunos cabildos que estuvieron abiertos a la población ciudadana, como por ejemplo el de Hamburgo, pero ésta era una ciudad en la que desde muy temprano se había prohibido el asentamiento de caballeros y nobles, y estaba situada además en un ámbito en que la pequeña nobleza independiente apenas había alcanzado desarrollo, a diferencia de Suabia y Renania ${ }^{71}$.

Y no cabe duda de que esta insistencia en presentar a los vecinos de las ciudades como personas de rango sociopolítico inferior al de los nobles que habitaban en los castillos y casas fuertes del campo, que conllevaba además una evidente discriminación para los primeros en cuestiones tan importantes como el acceso a los cabildos catedrales, debió influir en la decisión de abandono de las ciudades tomada por cuantas familias aspiraban

\footnotetext{
${ }^{66}$ Vid.Rolf KIESSLING, Bürgerliche Gesellschaft und Kirche in Augshurg im Spätmittelalter, Augsburgo. 1971, p. 32

${ }^{67}$ Ibid. pp. 323 y ss.

${ }^{68}$ Vid. G. FouQET. Das Speyerer Domkapitel im Späten Mittelalter (ca. 1350-1540), Maguncia, 1987.

(1)Vid. M. Hollmann, Das Mainzer Domkapitel im Späten Mittelalter (1306-1476), Maguncia, 1990. El estatuto que prohibió la entrada de no nobles al cabildo fue aprobado en Maguncia en 1326.

${ }^{70}$ Vid. H. LIEBERICH, op. cit. p. 76.

${ }^{71}$ Vid. O. BRUNNER, Hamburg, p. 327.
} 
a que se les siguiese reconociendo su condición noble. Y de hecho a las corporaciones de la pequeña nobleza que se terminaron consolidando sobre todo en el ámbito suabo y renano a fines de la Edad Media, y persistieron hasta el final del Antiguo Régimen, sólo tuvieron acceso personas no avecindadas en ciudades, con la excepción de los vecinos de Estrasburgo, que pudieron compatibilizar la condición de ciudadanos con la de miembros de las corporaciones nobiliarias alsacianas ${ }^{72}$.

En resumidas cuentas entendemos que el siglo XIII representó en el proceso de evolución de la estructuración sociopolítica de la ciudades alemanas un período de inflexión y al mismo tiempo de transición, puesto que durante el mismo se sentaron definitivamente las bases que permitieron la consolidación del estamento ciudadano como tercer elemento de la organización estamental de la población laica junto con nobleza y campesinado, si bien la pervivencia de elementos de la herencia del pasado conllevó el que este estamento todavía no adquiriese entonces su perfil definitivo, como lo prueba la persistencia de elementos privilegiados en las sociedades políticas urbanas durante este siglo, constituidos en su mayoría por familias de origen ministerial. Estos elementos privilegiados fueron los caballeros, que la documentación del siglo XIII permite identificar en muchas ciudades alemanas. Y aunque se ha discutido mucho sobre si descendían de ministeriales o procedían de familias de la nobleza rural que habían emigrado a las ciudades, hoy por hoy los argumentos de más peso nos llevan a inclinarnos por la primera hipótesis explicativa. Pero dejando a un lado este problema, el hecho indiscutible es que la presencia de estos elementos privilegiados representó en las ciudades alemanas del siglo XIII un fenómeno residual, y que los mismos fueron desapareciendo poco a poco de ellas, porque la tendencia que se estaba imponiendo era hacia la total uniformización del estatuto jurídico de la población urbana.

\section{Nobleza y ciudades en Castilla en el siglo XIII}

Paradójicamente el panorama que en los siglos plenomedievales presentaron la mayoría de las ciudades castellanas estuvo mucho menos marcado que en el caso de las alemanas por la presencia en su seno de

\footnotetext{
${ }^{72}$ Vid. A. OVERmann. Die Reichsritterschaft im Unterelsass bis zum Beginn des dreissigjälrringen Krieges, "Zeitschrift für die Geschichte des Oberrheins", 50 (1986), pp. 570637.
} 
grupos nobiliarios, o al menos de estamentos privilegiados con rasgos próximos a los de la nobleza. Y, según nuestro punto de vista, este hecho respondería en gran medida a la menor impronta "señorial". de las estruturas políticas en la mayor parte de las ciudades del reino castellano-leonés durante estos siglos, y muy en particular en las realengas, que, salvo en Galicia y la Cornisa Cantábrica, eran las más numerosas.

El menor desarrollo de las estructuras señoriales en las ciudades castellanas plenomedievales propició que en las mismas se consolidase un sistema social que en el contexto europeo del momento destacaba por su carácter más abierto, y por estar menos coartado por las trabas propias del mundo feudoseñorial, con sus privilegios estamentales y restricciones impuestas a las personas en la libre capacidad de disposición de sus bienes y cuerpos. Y esta mayor apertura del sistema social en las ciudades castellanas de la repoblación entre los siglos XI y XIII se tradujo por ejemplo en que la población servil, todavía relativamente numerosa en la mayoría de las ciudades alemanas hasta el propio siglo XIII, estuviese en aquéllas prácticamente ausente, y en que todavía no se llegasen a consolidar en ellas en estos siglos grupos formalmente privilegiados.

En los fueros de algunas ciudades se incluyeron incluso disposiciones que imponían a los individuos de condición noble, ricoshombres o infanzones, que acudiesen a avecindarse a las mismas o a sus territorios jurisdiccionales la renuncia a sus privilegios estamentales, y la obligación de someterse a la misma normativa jurídica que el resto de los vecinos de condición pechera $^{73}$. Estas disposiciones, y otras orientadas a evitar que el ejercicio del poder político tendiese a personalizarse en exceso ${ }^{74}$, respondían por consiguiente a una filosofía política que participaba de los mismos principios de carácter consociativo que animaron las constituciones políticas de las ciudades alemanas en época posterior, y ello a pesar de que en las ciudades castellanas en cuyos fueros se expresó no fueron precisamente los mercaderes implicados en el comercio a larga distancia los que imprimieron originalidad a sus estructuras sociales.

\footnotetext{
${ }^{73}$ Un ejemplo nos lo proprociona el fuero de Soria, en su título XXVIII, epígrafe 271. Desarrollamos esta cuestión en Caballeros e hidalgos en la Extremadura castellana medieval (siglos $X I I-X V$ ), "En la España Medieval", 15 (1992), pp. 44 y ss.

${ }^{74}$ Damos cuenta de la inclusión de este tipo de disposiciones en el fuero de Soria en Estructuras de poder en Soria a fines de la Edad Media. Valladolid, 1993, pp. 208 y ss.
} 
Por ello entendemos que no se pueden explicar las peculiaridades político-institucionales de las ciudades a partir del perfil socioeconómico de su población, o viceversa, advirtiéndose que en última instancia los modelos explicativos que siguen esta línea se basan en el intento de vincular a la burguesía capitalista del siglo XIX con el estamento "burgués" o ciudadano de las sociedades del Antiguo Régimen, y de presentar a ambos grupos como los paladines en la lucha por la implantación de formas de gobierno progresistas y democráticas.

Las ciudades castellanas entre los siglos XI y XIII, haciendo excepción de algunas pocas al norte del Duero, fueron centros de asentamiento de una población muy escasamente interesada por las actividades mercantiles o de producción artesanal para la exportación. Por el contrario sus grupos dominantes se interesaron sobre todo por las actividades militares a través del combate a caballo, adoptando así un modo de vida muy próximo al de la nobleza, sin que sin embargo su posición en el contexto de las estructuras político-institucionales de sus ciudades presentase inicialmente los rasgos propios de un estamento nobiliario. Ciertamente el hecho de que en la mayoría de las ciudades castellanas los caballeros terminasen monopolizando el ejercicio del poder local, justifica el que se les pueda considerar como una auténtica aristocracia urbana, evitando en cualquier caso el calificativo de noble ${ }^{75}$. Pero ello no nos debe llevar a extraer falsas conclusiones sobre la caracterización de las estructuras sociales de las ciudades castellanas plenomedievales, y por extensión de los territorios rurales que tenían asignados como ámbito jurisdiccional, y que presenta un notable contraste con las que dentro del mismo reino de Castilla estaban vigentes en los ámbitos de dominio señorial de la nobleza laica y eclesiástica. En efecto, en estos últimos regían unos principios políticos de carácter jerárquico, por más que los titulares de los señoríos tolerasen la existencia del concilium en el que se agrupaban los vasallos, y unas formas de transmisión del ejercicio del poder que propiciaban que éste se considerase como una prerrogativa personal, justificada por el propio sistema feudovasallático y los procedimientos de reparto de herencia establecidos en el seno

\footnotetext{
${ }^{75}$ José Maria MiNGUEz llama la atención sobre la necesidad de diferenciar entre aristocracia y nobleza. Entiende que las aristocracias urbanas castellanas surgieron de un proceso de fusión entre burguesía y caballería villana, que se iniciaría en la segunda mitad del siglo XII. Vid. La transformación social de las ciudades y las Cortes de Castilla y León, en "Las Cortes de Castilla y León en la Edad Media". Cortes de Castilla y León. 1988. p. 22.
} 
de los linajes nobles. En las ciudades, sin embargo, los caballeros ejercían el poder por el hecho de haber sido elegidos por sus collaciones, y no tenían ningún derecho a ocupar los oficios con carácter vitalicio, sino que éstos se solían renovar anualmente, y sólo gozaban de determinados privilegios en los terrenos político y socioeconómico en la medida en que se podían permitir mantener caballo y armas, y servir a la ciudad y al rey con ellos.

Distintos autores han insistido en poner de manifiesto el carácter aristocrático de estos grupos de caballeros que controlaron el gobierno de la mayoría de las ciudades castellanas en los siglos plenomedievales, pero, aunque no negamos que les asiste razón, consideramos que conviene insistir en diferenciar la situación de los siglos XI, XII y gran parte del XIII respecto a la de la época posterior, y en consecuencia evitar caracterizar a las aristocracias urbanas de la primera época como si de un auténtico estamento nobiliario se tratase, puesto que en el sistema sociopolítico entonces vigente en las ciudades castellanas todavía no se reconocía la legitimidad de la existencia de estamentos en su seno, salvando por supuesto el caso de los clérigos. Por el contrario entendemos que la posición de las aristocracias de caballeros hasta fines del siglo XIII en la mayoría de las ciudades castellanas se asemeja más a la de los grupos oligárquicos de ciudades alemanas del tipo de Lübeck, donde, aunque formalmente todos los vecinos tenían reconocidos los mismos derechos y obligaciones, de hecho el control del gobierno estaba en manos de un grupo relativamente amplio de familias en estado de constante renovación en el transcurso de las generaciones. $\mathrm{Y}$ a este respecto hay que recordar que también en las ciudades alemanas en las que los grupos dominantes manifestaron una más decidida orientación hacia el comercio a larga distancia, sus representantes solían combatir a caballo, a diferencia del grueso de la población urbana, que combatía a pie, sin que por ello se les reconociese la condición de caballeros, reservada en el ámbito imperial a los miembros de la nobleza.

Por todo ello hay que mostrarse precavidos a la hora de presentar un panorama de las ciudades castellanas plenomedievales que trate de explicar la preferente orientación de las mismas hacia las actividades agropecuarias, y el escaso desarrollo del comercio y de la producción artesanal para la exportación, en función de la prepotencia sociopolítica alcanzada por los caballeros villanos, puesto que en primer lugar se constata que en ciudades como Burgos o Valladolid la condición de caballero villano era compatible con la de mercader, y en segundo lugar se advierte que el papel que las estructuras sociopolíticas urbanas asignaban a los caballeros en muy poco 
difería del desempeñado en ciudades de la Europa del Norte por oligarquías de mercaderes, convencionalmente calificadas como "burguesas". Y por el contrario las situaciones de consolidación de estamentos laicos formalmente privilegiados en el seno de las sociedades urbanas fueron mucho más frecuentes hasta fines del siglo XIII en el ámbito del Imperio alemán que en el de la Corona de Castilla, donde las encontramos por primera vez perfectamente definidas en las ciudades andaluzas conquistadas durante ese siglo, puesto que, desde el propio momento de su repoblación, en ellas se reconoció una posición privilegiada a los repobladores de origen noble o hidalgo, a diferencia de como se había procedido en las anteriores fases de la repoblación ${ }^{76}$.

Así pues también en este terreno las ciudades andaluzas se mostraron pioneras en la adopción de unas formas de organización social y política que luego fueron más o menos directamente imitadas por el resto de las grandes ciudades castellanas. $\mathrm{Y}$ entre las primeras que entró por este camino de "imitación" habría que destacar a Valladolid, donde ya a fines del siglo XIII tuvo lugar la consolidación definitiva de un estamento hidalgo en el seno de la población urbana, al conceder Sancho IV en 1293 un privilegio a los caballeros de la ciudad por el que quedaron reconocidos como hidalgos ellos y sus descendientes ${ }^{77}$. Durante la primera mitad del siglo XIV se debieron producir fenómenos semejantes en muchas de las ciudades castellanas, y así tuvimos ocasión de comprobarlo en un trabajo dedicado a Soria, ciudad en la que un privilegio de Pedro I de 1365 ya diferencia claramente entre "cavalleros escuderos fijosdalgo de los linajes" y "cavalleros que an quantias para mantener armas e cavallo", también conocidos como "cavalleros que escusan pechos", es decir entre caballeros hidalgos y caballeros de cuantía, éstos últimos de condición no noble ${ }^{78}$.

A la luz de estos ejemplos tomados de Valladolid y Soria, entendemos por lo tanto que el profesor Teófilo F. Ruiz exagera el contraste existente entre las ciudades andaluzas y las ciudades del norte de Castilla, cuando alude al hecho de que en las primeras podían residir los nobles y participar en la vida política, mientras que en las segundas éstos, al menos

\footnotetext{
${ }^{76}$ Vid. Manuel González Jiménez, Las Cortes, pp. 359 y ss.

${ }^{77}$ Vid. A. RucquoI, Valladolid en la Edad Media, Junta de Castilla y León, Valladolid, 1987, vol. I, pp. $140-3$ y 239.

${ }^{78}$ Vid, nuestro artículo Caballeros e hidalgos en la Extremadura castellana medieval (Siglos XII-XV), "En la España Medieval", 15 (1992), pp. 31-62.
} 
hasta finales del siglo XIV, aunque estaban exentos de la jurisdicción municipal, también quedaban excluídos del disfrute de los derechos de vecindad $^{79}$. A este respecto en primer lugar hay que puntualizar diciendo que los estatutos que en algunas ciudades castellanas prohibieron durante los siglos XIV y XV el avecindamiento de nobles iban dirigidos exclusivamente contra los miembros de la alta nobleza, y no contra los hidalgos en general, que de hecho abundaban entre su población ${ }^{80}$. Y en cualquier caso ya a raíz de la creación de los regimientos durante el reinado de Alfonso XI el gobierno de las principales ciudades de la submeseta norte quedó de hecho reservado a los hidalgos urbanos, sin duda en su mayoría descendientes de antiguos caballeros villanos, que para repartirse los principales oficios de gobierno local se organizaron en muchas de ellas en linajes ${ }^{81}$.

De hecho el profesor Teófilo $F$. Ruiz no advierte que en muchas de las ciudades de la submeseta norte, y también de otros ámbitos del reino de Castilla, los caballeros villanos terminaron convirtiéndose en hidalgos, al tiempo que se consolidaban como grupo oligárquico cerrado, y que bastantes de los que repoblaron las ciudades andaluzas en calidad de caballeros hidalgos procedían de hecho de familias de caballeros villanos del Norte ${ }^{82}$. $\mathrm{Y}$ por ello entendemos que lo que ocurrió en las ciudades andaluzas a mediados del siglo XIII fue un adelanto de lo que ya se estaba gestando en el resto de las ciudades de Castilla, tanto en lo referente a la pérdida de capacidad de autogobierno de las comunidades políticas urbanas, como en lo tocante a la consolidación de un estamento nobiliario en el seno de la población urbana, cuyos miembros pasarían a monopolizar ya no sólo de hecho sino también por derecho los principales oficios de gobierno local a partir del reinado de Alfonso XI.

\footnotetext{
${ }^{79}$ T.F. RuIz. Crisis and Continuity: Land and town in Late Medieval Castile. Philadelphia, 1994, p. 185-6.

${ }^{80} \mathrm{Se}$ aprobaron estos estatutos por ejemplo en Santo Domingo de la Calzada, para evitar el avecindamiento de los Leyva. Vid. nuestro artículo Santo Domingo de la Calzada en la Baja Edad Media. Aspectos de su organización político-institucional, Berceo, 130 (1996), p. 120. La ciudad de Soria, en la que abundaban los linajes de nobleza media, también se resistió a que se avecindasen en ella miembros de la alta nobleza. según demostramos en Estructuras de poder, pp. $171-176$

${ }^{81}$ Tratamos la cuestión en nuestro artículo El papel de los linajes en las estructuras de gobierno urbano en Castilla y en el Imperio alemán durante los siglos bajomedievales, "En la España Medieval", 20 (1997), pp. 143-177.

${ }^{82} \mathrm{Hemos}$ desarrollado estas tesis en nuestro artículo Caballeros e hidalgos, que no ha sido tenido en cuenta por T.F. RuIz en Crisis and Contimuity.
} 
Ciertamente hubo ciudades en Castilla en las que no se dio este fenómeno de la adscripción de los principales oficios de gobierno al estamento hidalgo, estuviese éste o no organizado en linajes ${ }^{83}$, pero la escisión de la población urbana en dos estamentos, el de pecheros y el de hidalgos, a los que sólo en casos excepcionales se añadió un tercero de ciudadanos, llegó a tener carácter prácticamente generalizado en los siglos bajomedievales y modernos ${ }^{84}$, contribuyendo así a que el paisaje sociopolítico de las ciudades castellanas se diferenciase decisivamente del de sus homólogas alemanas, en las que la población ciudadana conformaba un único estamento, perfectamente diferenciado de la nobleza y el campesinado que poblaban el campo. Y aunque fue en el siglo XIV cuando este contraste en la forma de estructuración estamental entre ciudades castellanas y alemanas pudo advertirse por primera vez de forma clara, tanto uno como otro modelo se encontraban ya en muy avanzado proceso de gestación a fines del siglo XIII.

\section{LAS HERMANDADES Y LIGAS URBANAS}

Aunque la evolución sociopolítica de las ciudades en Castilla y en el Imperio alemán durante el siglo XIII mostró preferentemente tendencias divergentes, hubo un terreno en el que se dio una curiosa coincidencia entre ambos ámbitos, dado que fue precisamente en esta época cuando los dos destacaron en el conjunto europeo por ser aquéllos en que adquirió mayor desarrollo el fenómeno de las ligas urbanas, concertadas para la persecución de objetivos políticos.

Estas confederaciones políticas promovidas por ciudades también adquirieron cierto desarrollo en otros ámbitos del Occidente europeo

\footnotetext{
${ }^{8:}$ En Logroño, por ejemplo, la existencia de tres estamentos (pecheros, ciudadanos e hidalgos) impidió al de los hidalgos ejercer una hegemonía incontrastada, hasta el punto de que en ocasiones llegó a aliarse al estamento de los pecheros para contrarrestar la fuerza del de los ciudadanos. Vid. nuestro artículo Conflictos estamentales por el control del gobierno municipal en Logroño a fines del XV y principios del XVI. "Cuadernos de Estudios Medievales y Ciencias y Técnicas Historiográticas". 17 (1992). pp. 205-225.

${ }^{84}$ Sólo en algunas pocas ciudades se sigue sin diferenciar en los siglos bajomedievales entre hidalgos y pecheros en el seno de la población urbana. Sería el caso de las villas guipuzcoanas de San Sebastián, Rentería y Fuenterrabia, según la tesis de $\mathrm{M}^{\mathrm{a}}$. Soledad Tena García, La sociedad urbana en la Guipuiscoa costera medieval: San Sebastian, Rentería y Fuenterrabia (1200-1500). San Sebastián. 1997.
} 
medieval, pero no tuvieron ni mucho menos difusión universal, y apenas fueron relevantes en dos ámbitos políticos de importancia central en la época, los reinos de Francia e Inglaterra. En Italia sí que alcanzaron un gran desarrollo, a la vez que mayor protagonismo político que en el Imperio alemán o en Castilla, pero en este ámbito, y más en particular en su mitad norte, fue durante el siglo XII cuando las ligas urbanas conocieron su época dorada, en el contexto de los enfrentamientos políticos con el emperador Federico Barbarroja ${ }^{85}$.

Por su parte en otros reinos de la Península Ibérica también está constatada la existencia de estas ligas, frecuentemente identificadas con el nombre de "hermandades", como es el caso del reino de Aragón, para el que ya hay referencias documentales del año $1226^{86}$. De hecho las hermandades aragonesas, por lo poco que sabemos de ellas, parece que guardaban ciertas similitudes con las castellanas, pero tuvieron un alcance bastante más modesto, pues también el reino de Aragón era bastante más reducido que el de Castilla, y sus ciudades muchas menos.

Por consiguiente se puede considerar al Imperio alemán por un lado y a la Corona de Castilla por otro como los dos ámbitos principales del Occidente europeo en los que durante el siglo XIII alcanzó máximo desarrollo el movimiento político de las ligas urbanas. Si analizamos con detenimiento el proceso de aparición de estas ligas en los dos ámbitos a partir de mediados del siglo XIII, observaremos, sin embargo, que no se trataba de dos fenómenos históricos equiparables, sino que les separaban profundas diferencias, como traducciones que eran de dos realidades sociopolíticas muy distintas. En efecto, mientras que las ciudades castellanas habían entrado ya en la segunda mitad del siglo XIII en un proceso de pérdida progresiva de sus atribuciones de autogobierno y de asimilación por parte de sus sectores dominantes de los ideales políticos nobiliarios, las alemanas estaban inmersas entonces en pleno proceso de conversión en

\footnotetext{
${ }^{85}$ Diversas contribuciones que analizan el papel de las ligas urbanas en Italia y Alemania en época medieval aparecen reunidas en un volumen de la serie "Vorträge und Forschungen". Vid. Helmut MAURER (ED.), Kommunale Bündnisse Oberitaliens und Oberdeutschlands im Vergleich, Sigmaringen, 1987.

${ }^{86}$ Las hermandades aragonesas no han sido objeto frecuente de la atención de los investigadores medievalistas. Hace algunas referencias a ellas Eugen WoHLHAUPTER, Studien zur Rechtsgeschichte der Gottes- und Landfrieden in Spanien, Heidelberg, 1933, pp. 490 y ss. Este autor se basa preferentemente en un artículo de MuÑoz CaSAYús, que no hemos podido consultar, titulado Las hermandades en Aragón, "Universidad. Revista de Cultura y Vida Universitaria", 4 (1927). pp. 669 y ss.
} 
entidades políticas autónomas, en las que se estaba imponiendo un sistema de gobierno de signo muy distinto al de carácter personalista propugnado por la nobleza, mucho más inspirado por los principios de carácter consociativo. $\mathrm{Y}$ estas circunstancias contribuyen a explicar que por un lado en Castilla la institución de la hermandad como asociación de ciudades orientada a la defensa de un proyecto político urbano, y no como mero instrumento de la monarquía o simple organización defensiva frente a los abusos de nobles convertidos en auténticos delincuentes, ya no volviese a hacer acto de presencia en el escenario histórico a partir del reinado de Alfonso XI, mientras que en Alemania durante los siglos XIV y XV las ligas urbanas alcanzaban sus momentos de máxima vitalidad, entrando en guerra contra nobles y príncipes poderosos, como el conde de Württemberg, y desafiando abiertamente la autoridad del rey, que reiteradamente las prohibió, por considerar que eran organizaciones políticas que escapaban totalmente a su control $^{87}$.

Ciertamente las ligas urbanas que se desarrollaron en Alemania en los siglos XIV y XV no fueron tan ambiciosas en sus objetivos como lo fue, al menos según algunos autores, la Liga Renana de 1254, que habría pretendido vertebrar el imperio según un modelo federativo en el que las entidades políticas urbanas tendrían voz y voto en igualdad de condiciones que príncipes y nobles ${ }^{88}$. Pero quizás esta reorıentación de sus objetivos obedeció a una valoración más acertada de la realidad política y de cuáles eran sus posibilidades, en el contexto de relación de fuerzas existente en el imperio. Y no cabe duda de que en 1254 las ciudades no estaban en

\footnotetext{
${ }^{87}$ Sería excesivamente prolijo citar toda la bibliografía que ha abordado aspectos de la historia de las hermandades y ligas urbanas en Castilla y Alemania en época medieval. Para Castilla destacaríamos un estado de la cuestión reciente realizado por J.M ${ }^{\mathrm{a}}$. MíNGUEZ en Las hermandades generales de los concejos en la Corona de Castilla (Objetivos, estructura interna y contradicciones en sus manifestaciones iniciales), "Concejos y ciudades en la Edad Media...", pp. 539-567. Entre otros títulos que contribuyen a ilustrar la historia de las ligas urbanas en Alemania en los siglos XIV y XV se pueden destacar Jörg FÜCHTNER, Die Bündnisse der Bodenseestädte bis zum Jahre 1390, Göttingen, 1970. Harro BLEZINGER, Der Schwäbische Städtebund in den Jahren 1438-1445, Stuttgart, 1954. Y Helmo HESSLINGER, Die Anfänge des Schwäbisches Bundes. Ein Beitrag zur Geschichte des Einungswesens und der Reichsreform unter Kaiser Friedrich III, Ulm, 1970.

${ }^{88}$ Desarrolla estas tesis, insistiendo quizás demasiado en presentar a las ciudades como paladines de una reforma del imperio "avant la lettre", Erich BIELFELDT, Der Rheinische Bund von 1254. Ein erster Versuch einer Reichsreform, Kiel, 1937. Repasa otras interpretaciones de la significación histórica de la Liga Renana Arno BuschmanN, Der Rheinische Bund von 12541257. Landfriede, Städte, Fürsten und Reichsverfassung im 13. Jahrhundert, en Helmut MAURER (Ed.) op. cit. pp. 167-212.
} 
condiciones todavía de conseguir que se hiciesen realidad objetivos tan ambiciosos, puesto que entonces sólo habían alcanzado un notable grado de madurez política unas pocas ciudades de señorío episcopal, mientras que muchas de las de señorío regio que en los siglos bajomedievales llegarían a adquirir gran protagonismo, como Nürnberg y la mayoría de las ciudades de Suabia, estaban entonces comenzando a despertar a la conciencia política. Por lo tanto, a pesar de que se llegasen a plantear objetivos políticos maximalistas, la Liga Renana de 1254 se puede considerar como una primera etapa en el proceso de afianzamiento del papel político de las ciudades en el imperio, que siguió avanzando durante los siglos XIV y XV, y que en el ámbito de la actual Suiza, entonces todavía formalmente integrado en el imperio, dio frutos que han pervivido hasta la actualidad.

Las hermandades castellanas del XIII por el contrario surgieron ya afectadas por una profunda contradicción, ya que en primer lugar se sirvieron de un instrumento asociativo para la defensa de unos intereses particularistas locales ${ }^{89}$, y en segundo lugar adquirieron su máximo despliegue en el mismo período de tiempo en que las oligarquías urbanas estaban empezando a abandonar su compromiso en la defensa del régimen de gobierno urbano para volcarse en el servicio a la monarquía, a cambio de percibir de ésta una serie de contraprestaciones por su renuncia al liderazgo del sistema urbano. $\mathrm{Y}$ en este contexto se explica por ejemplo la probable relación que el profesor Mínguez apunta entre la pasividad con que los líderes de la Hermandad General aceptaron la disolución decretada por Alfonso XI en 1325 y la consiguiente difusión del sistema de regimiento en toda Castilla ${ }^{90}$.

De hecho uno de los factores que más contribuye a diferenciar las hermandades castellanas de las ligas urbanas alemanas es su distinta base social, porque las primeras no eran propiamente un instrumento para la defensa de los intereses políticos de un estamento ciudadano en ascenso, a diferencia de las alemanas que sí que lo fueron, tanto en el siglo XIII como en el XIV y en el XV. En efecto la progresiva conversión de las oligarquías de las ciudades castellanas en cerradas agrupaciones estamentales nobles no proporcionaba la base de partida más adecuada para que las hermandades se convirtiesen en instrumento de canalización del antagonismo entre nobleza

\footnotetext{
${ }^{89}$ Llama la atención sobre esta contradicción J.M ${ }^{\mathrm{a}}$. MínguEZ, op. cit. p. 566.

${ }^{90} \mathrm{~J} . \mathrm{M}^{\mathrm{a}}$. MínGUEZ, op. cit. p. 556.
} 
y estamento ciudadano. $\mathrm{Y}$ por el contrario las ligas urbanas alemanas con frecuencia sí que tuvieron esta orientación antinobiliaria, que respondía a la profunda fractura existente en el ámbito alemán entre el estamento ciudadano (Bürgertum) y la nobleza. Y así por ejemplo es significativo que ya una de las primeras ligas urbanas de carácter regional constatada en Alemania, la que en 1226 formaron Maguncia, Bingen, Worms, Spira, Frankfurt, Gelnhausen y Friedberg, terminó siendo prohibida por el rey Enrique VII a instancias del arzobispo de Maguncia, quien consideraba que iba dirigida contra sus intereses y los del obispo de Worms, mientras que pocos años después este mismo monarca también prohibió la liga de las ciudades del obispado de Lieja, a instancia de nuevo de los príncipes, en el Reichstag de Worms de $1231^{91}$.

Las ligas urbanas alemanas continuaron teniendo durante toda la época bajomedieval una clara orientación antinobiliaria, a pesar de que en bastantes ocasiones admitiesen a príncipes y nobles en su seno, pero en Castilla a partir de mediados del siglo XIV una actuación abiertamente antinobiliaria por parte de las ciudades se hizo inviable, debido a que desde entonces el gobierno de los principales núcleos urbanos castellanos estuvo controlado por miembros de la nobleza. En la época de máximo desarrollo de las hermandades castellanas, es decir a finales del siglo XIII y comienzos del siglo XIV, todavía no se había consolidado esta situación, y salvo en el caso de las ciudades andaluzas de fuero de Toledo, los grupos gobernantes urbanos seguían siendo formalmente abiertos y mantenían una cierta diferenciación con respecto a la nobleza rural de ricos hombres e infanzones. $\mathrm{Y}$ esta mayor permeabilidad de las estructuras sociopolíticas urbanas en aquellos momentos debió favorecer sin duda la aparición de las hermandades, pero la evolución de estas mismas estructuras sociopolíticas hacia modelos más oligárquicos, y más determinados por el peso sociopolítico y cultural de la nobleza, estaba ya entonces en marcha y en muchas ciudades incluso en proceso muy avanzado, circunstancia que sólo podía influir negativamente sobre las perspectivas de futuro de las hermandades,

\footnotetext{
${ }^{91}$ Vid. Erich BIELFELDT. op. cit. p. 14. Un factor que al parecer alimentó la animadversión de los señores y príncipes hacia estas ligas es que las ciudades se habían comprometido a atraer el máximo número posible de población dependiente, procedente de los dominios rurales de la nobleza y los príncipes, a pesar de que esta práctica ya había sido prohibida por decreto imperial en 1220.
} 
entendidas como asociaciones de ciudades encaminadas a la persecución de unos objetivos políticos propios.

Un factor también muy importante que hay que tener en cuenta para explicar la temprana decadencia de las hermandades castellanas, puesta en relación con el fenómeno de la expansión de las ligas urbanas en Alemania en los siglos XIV y XV, es el del proceso de fortalecimiento del poder regio en Castilla, que, aunque con altibajos, manifestó una clara tendencia ascendente durante estos mismos siglos. Y por esta razón las ciudades castellanas no se vieron tan expuestas a los ataques indiscriminados de la nobleza como las alemanas, ni tuvieron que recurrir con tanta frecuencia como éstas a los procedimientos de la autodefensa, porque los reyes de Castilla se encontraban en mejor disposición de garantizar el respeto de la normativa jurídica por todas las instancias sociopolíticas del reino, incluída la alta nobleza, que sus homólogos alemanes. No obstante, hubo también momentos durante el siglo XV en que la monarquía se mostró relativamente incapaz de garantizar este respeto, y a pesar de ello no resurgieron entonces con vigor las hermandades de ciudades.

Entrar en el análisis pormenorizado y explicación de estos procesos que cubren todo el período cronológico de la Baja Edad Media nos habría de llevar, sin embargo, muy lejos, excediendo con mucho el marco fijado para el presente trabajo. $Y$ no es nuestra intención plantear aquí de forma sistemática un análisis comparativo del papel histórico de las hermandades y ligas urbanas en Castilla y Alemania durante el Medievo, sino que simplemente hemos querido detenernos brevemente a reflexionar sobre esta cuestión para advertir cómo la aparición de estas dos realidades políticas en ambos ámbitos durante el siglo XIII no se puede interpretar como indicio de la confluencia de las tendencias evolutivas de las estructuras sociopolíticas urbanas en un mismo sentido en los dos territorios.

\section{RÉSUMÉ}

Pendant le XIII siècle les villes européennes ont éprouvé des profondes transformations. Dans cet article $l^{\prime}$ auteur montre comme les villes castillanes et allemandes ont alors évolué d'une manière trés différente, et en conséquence pendant le Bas Moyen Âge elles ont montré une image aussi très différente les unes des autres du point de vue de leurs structures politiques et sociales. Il étudie le processus d'acquisition par les villes allemandes de leur autonomie politique pendant le XIIIè. siècle, et après le processus que a eu lieu à la même époque dans les villes castillanes de perte de leur capacité de autogouvernement. Les 
changements dans les structures sociales des villes en Castille et Allemagne sont aussi étudiés, et il est démontré que pendant le XIIIè. siècle la noblesse urbaine tombe en déchéance en Allemagne, tandis que dans les villes castillanes les nobles commencent à devenir le groupe social dominant.

\section{SUMMARY}

During the thirteenth century the European towns underwent deep transformations. In this article the author tries to show how the Castilian towns on one side and the German ones on the other side evolved in two opposed ways at that time, and as a consequence they offered a very different political and social profile during the Late Middle Ages. He pays attention to the process of acquisition of political autonomy by the German towns during the thirteenth century, and to the simultaneous process that caused the Castilian towns to be deprived of the capacity of self-government they had enjoyed before. The social changes that took place in the German and Castilian towns are also analysed, and it is proved that in Germany during the thirteenth century began the process of decline of the urban nobility, while on the other side in Castile another process started, at the end of which the nobility became the dominant group in most towns. 